Prepared in cooperation with the U.S. Army Corps of Engineers

\title{
Water Temperature Effects from Simulated Dam Operations and Structures in the Middle Fork Willamette River, Western Oregon
}

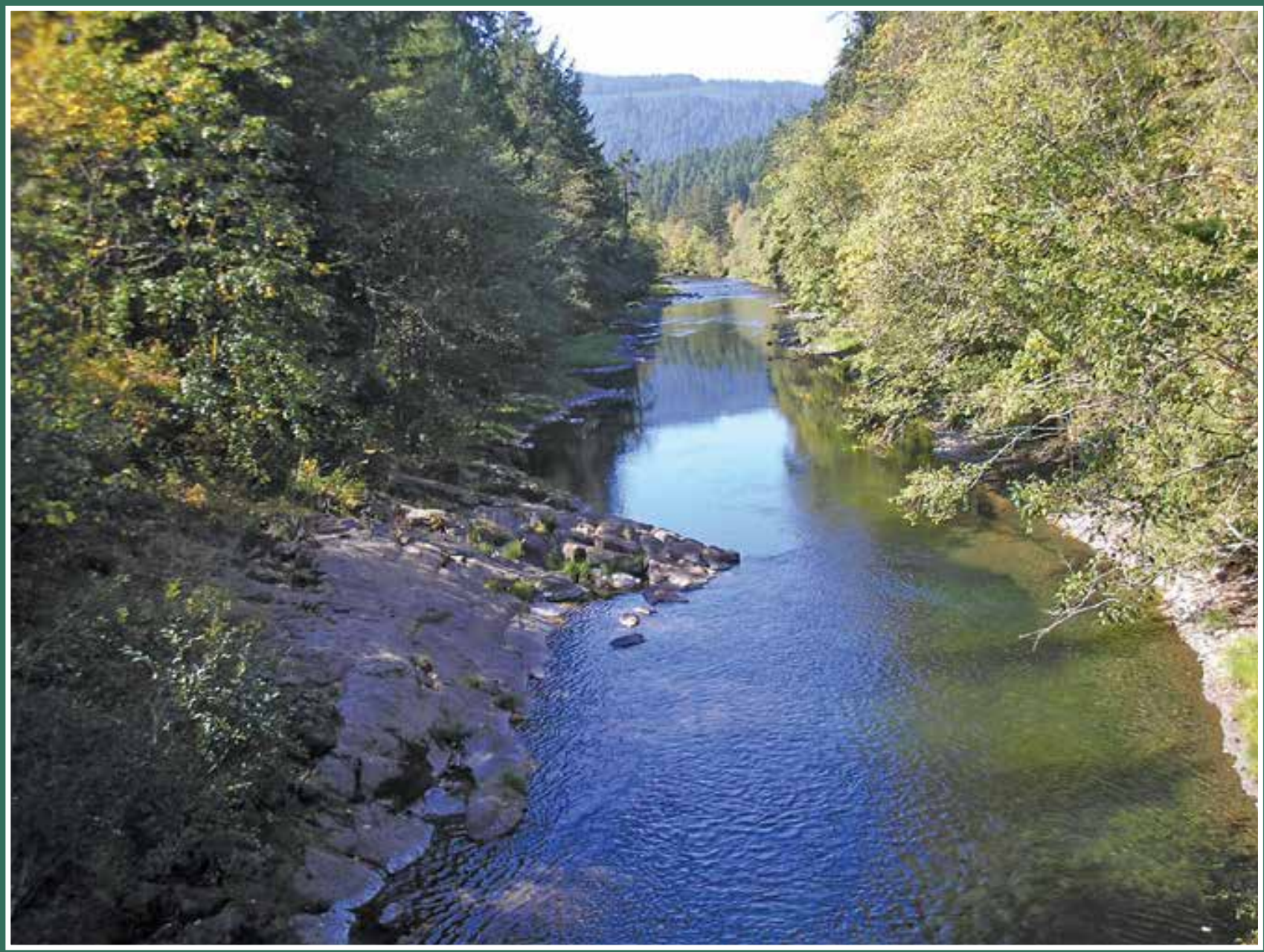

Open-File Report 2016-1159 
Covers: Photograph of North Fork of Middle Fork Willamette River, Oregon. Photograph by Benjamin Beal, U.S. Geological Survey, 2012. 


\section{Water Temperature Effects from Simulated Dam Operations and Structures in the Middle Fork Willamette River, Western Oregon}

By Norman L. Buccola, Daniel F. Turner, and Stewart A. Rounds

Prepared in cooperation with the U.S. Army Corps of Engineers

Open-File Report 2016-1159 


\section{U.S. Department of the Interior \\ SALLY JEWELL, Secretary}

\section{U.S. Geological Survey \\ Suzette M. Kimball, Director}

U.S. Geological Survey, Reston, Virginia: 2016

For more information on the USGS—-the Federal source for science about the Earth, its natural and living resources, natural hazards, and the environment-visit http://www.usgs.gov or call 1-888-ASK-USGS (1-888-275-8747)

For an overview of USGS information products, including maps, imagery, and publications, visit http://store.usgs.gov

Any use of trade, firm, or product names is for descriptive purposes only and does not imply endorsement by the U.S. Government.

Although this information product, for the most part, is in the public domain, it also may contain copyrighted materials as noted in the text. Permission to reproduce copyrighted items must be secured from the copyright owner.

Suggested citation:

Buccola, N.L., Turner, D.F., and Rounds, S.A., 2016, Water temperature effects from simulated dam operations and structures in the Middle Fork Willamette River, western Oregon: U.S. Geological Survey Open-File Report 2016-1159, 39 p., http://dx.doi.org/10.3133/ofr20161159.

ISSN 2331-1258 (online) 


\section{Contents}

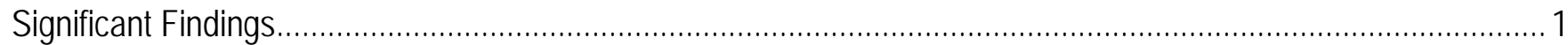

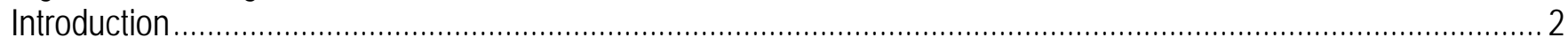

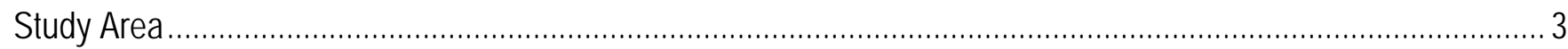

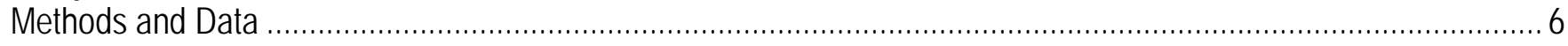

Model Description …………………………………

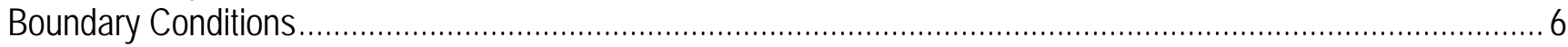

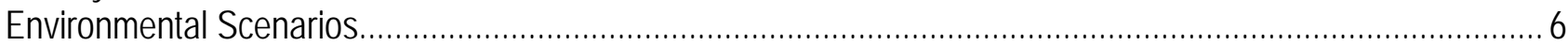

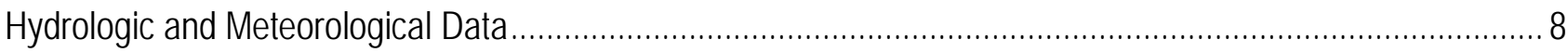

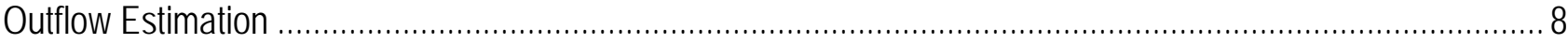

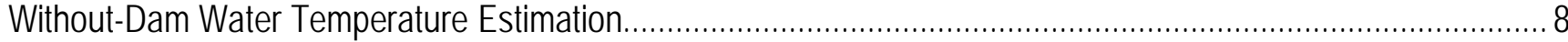

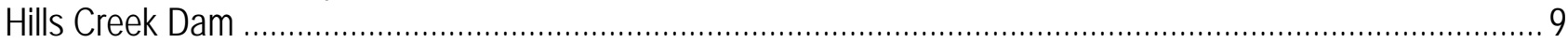

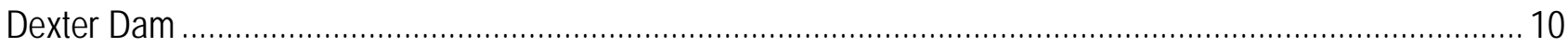

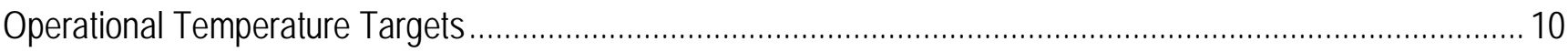

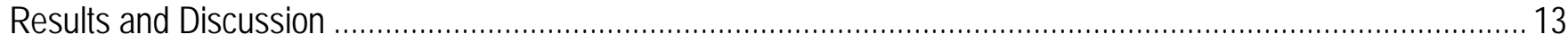

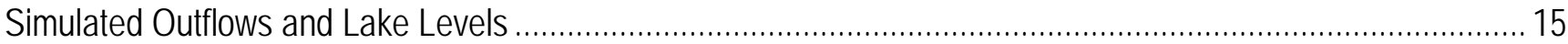

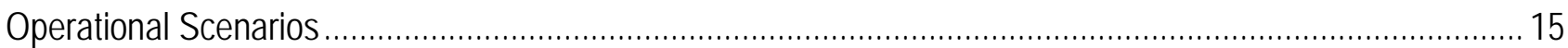

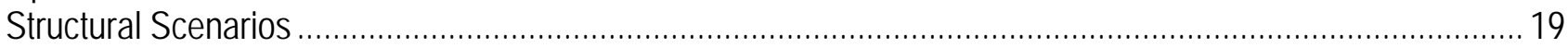

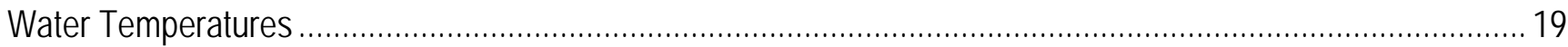

Hill Creek Dam Scenario Effects on Middle Fork Willamette River Upstream of Lookout Point Dam ................. 21

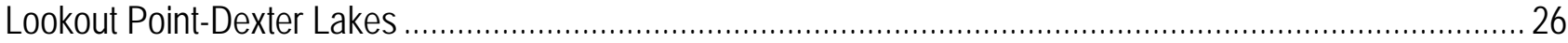

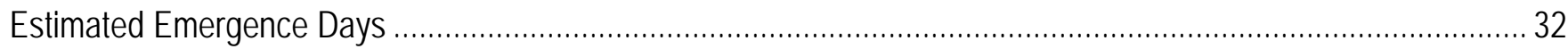

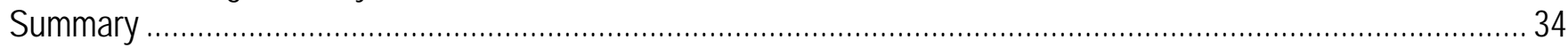

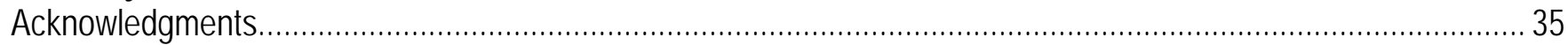

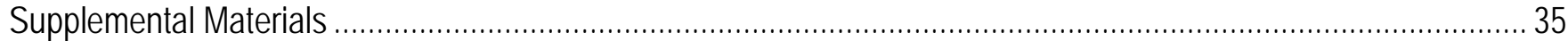

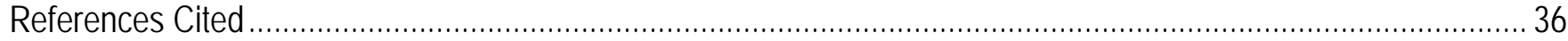

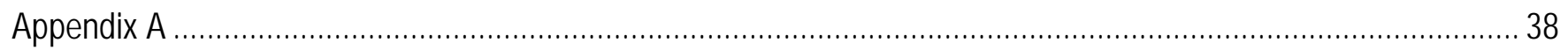

\section{Figures}

Figure 1. Map showing Middle Fork Willamette River study area, Oregon...................................................... 4

Figure 2. Diagrams showing elevations of operational goals and structures for Hills Creek, Lookout Point, and

Dexter Dams, Oregon

Figure 3. Graph showing total streamflow into Hills Creek Lake, Oregon, under environmental scenarios along with historical percentiles for 1936-2011.

Figure 4. Graph showing operational temperature target for Hills Creek Lake, showing without-dams daily mean temperature estimates for 1956-2014, and with-dam daily mean temperature measurements,

Middle Fork Willamette River, Oregon, 1978-2015

Figure 5. Graph showing operational temperature target downstream of Dexter Dam, showing without-dams daily mean temperature estimates for 2001-2014, and with-dam daily mean temperature measurements, Middle Fork Willamette River, Oregon, 1978-2015

Figure 6. Graphs showing simulated release rates from (A) Hills Creek Lake (HCR), and (B) Dexter Lake (DEX), Oregon, under various operational scenarios and averaged across wet, normal, and dry environmental scenarios, January-December. 
Figure 7. Graphs showing simulated range in lake levels at (A) Hills Creek Lake (HCR), and (B) Lookout Point Lake (LOP), Oregon, under multiple operational model scenarios averaged across wet, normal, and dry environmental scenarios, January-December.

Figure 8. Diagrams showing calculated 15-day average streamflow contributions (percentage) from tributaries to the Middle Fork Willamette River in the reach between Hills Creek Dam and Lookout Point Lake, Oregon.

Figure 9. Graph showing simulated release water temperatures under various operational and structural scenarios downstream of Hills Creek Lake, Oregon, averaged across wet, normal, and dry scenarios, June-December .....

Figure 10. Diagrams showing simulated average (A) and range (B) of release water temperatures across wet, normal, and dry scenarios in 15-day intervals under operational and structural scenarios at Hills Creek Dam, Oregon.

Figure 11. Diagrams showing simulated average (A) and range (B) of water temperature at the head of Lookout Point Lake across wet, normal, and dry scenarios in 15-day intervals under operational and structural scenarios at Hills Creek Dam, Oregon..

Figure 12. Graph showing simulated percent spill from Hills Creek Dam, Oregon under various operational and structural scenarios, averaged across wet, normal, and dry scenarios, January-December.

Figure 13. Graphs showing simulated release water temperatures immediately downstream of Dexter Dam, Oregon, under operational and structural scenarios averaged across wet, normal, and dry scenarios at (A) Hills Creek Dam and (B) Lookout Point Dam, June-December.

Figure 14. Graph showing simulated percent spill from Lookout Point Dam, Oregon, under various operational and structural scenarios averaged across wet, normal, and dry scenarios, January-December 28

Figure 15. Graph showing simulated average release water temperature downstream of Dexter Dam, Oregon, in 15-day intervals over wet, normal, and dry scenarios from various operational and structural scenarios at Hills Creek and Lookout Point Dams.

Figure 16. Graph showing simulated average release water temperature daily range at Dexter Dam, Oregon, in 15-day intervals over wet, normal, and dry scenarios from various operational and structural scenarios at Hills Creek and Lookout Point Dams.

\section{Tables}

Table 1. Description of environmental scenarios and percentiles of inflows for Hills Creek Lake, Oregon, 1935-2011

Table 2. Operational model scenario groups and associated refill, drawdown, and minimum lake elevation, Hills Creek and Lookout Point Dams, Oregon

Table 3. Structural model scenarios and associated model parameter settings, Hills Creek and Lookout Point Dams, Oregon

Table 4. Specification of power constraints, maximum lake elevations, refill and drawdown schedules, and outlet schemes for each operational and structural model scenario at Hills Creek and Lookout Point and Dams, Oregon

Table 5. Percent spill for releases under operational and structural scenarios, where the minimum, mean, and maximum percentages are from annual averages for each of the environmental scenarios (wet, normal, and dry), Hills Creek Dam, Oregon.

Table 6. Percent spill for releases from Lookout Point Lake, Oregon. under operational and structural scenarios, where the minimum, mean, and maximum percentages are from annual averages for each of the environmental scenarios (wet, normal, and dry)

Table 7. Estimated emergence day for a range of locations and model scenarios, based on Accumulated Thermal Unit calculations starting on day 263 of the year and ending at 1,750 degree Fahrenheit-days. 


\section{Conversion Factors}

Inch/Pound to International System of Units

\begin{tabular}{lcl}
\hline & \multicolumn{1}{c}{ Multiply } & \multicolumn{1}{c}{ Bo obtain } \\
\hline & Length & \\
\hline foot $(\mathrm{ft})$ & 0.3048 & meter $(\mathrm{m})$ \\
mile $(\mathrm{mi})$ & 1.609 & kilometer $(\mathrm{km})$ \\
\hline & Area & \\
\hline square mile $\left(\mathrm{mi}^{2}\right)$ & 2.590 & square kilometer $\left(\mathrm{km}^{2}\right)$ \\
\hline & Volume & \\
\hline acre-foot $($ acre-ft) & 1,233 & cubic meter $\left(\mathrm{m}^{3}\right)$ \\
\hline & Flow rate & \\
\hline cubic foot per second $\left(\mathrm{ft}^{3} / \mathrm{s}\right)$ & 0.02832 & cubic meter per second $\left(\mathrm{m}^{3} / \mathrm{s}\right)$ \\
\hline
\end{tabular}

International System of Units to Inch/Pound

\begin{tabular}{lll}
\hline \multicolumn{1}{c}{ Multiply } & By & \multicolumn{1}{c}{ To obtain } \\
\hline meter $(\mathrm{m})$ & Length & \\
kilometer $(\mathrm{km})$ & 3.281 & foot $(\mathrm{ft})$ \\
& 0.6214 & mile (mi) \\
\hline cubic meter $\left(\mathrm{m}^{3}\right)$ & Volume & \\
\hline & 0.0008107 & acre-foot (acre-ft) \\
\hline cubic meter per second $\left(\mathrm{m}^{3} / \mathrm{s}\right)$ & Flow rate & \\
\hline
\end{tabular}

Temperature in degrees Celsius $\left({ }^{\circ} \mathrm{C}\right)$ may be converted to degrees Fahrenheit $\left({ }^{\circ} \mathrm{F}\right)$ as ${ }^{\circ} \mathrm{F}=\left(1.8 \times{ }^{\circ} \mathrm{C}\right)+32$.

Temperature in degrees Fahrenheit $\left({ }^{\circ} \mathrm{F}\right)$ may be converted to degrees Celsius $\left({ }^{\circ} \mathrm{C}\right)$ as ${ }^{\circ} \mathrm{C}=\left({ }^{\circ} \mathrm{F}-32\right) / 1.8$.

\section{Datums}

Unless otherwise noted, vertical coordinate information is referenced to the North American Vertical Datum of 1988 (NAVD 88).

Horizontal coordinate information is referenced to the North American Datum of 1983 (NAD 83).

Elevation, as used in this report, refers to distance above the vertical datum. 


\section{Abbreviations and Acronyms}

$\begin{array}{ll}\text { ATU } & \text { accumulated thermal unit } \\ \text { BiOp } & \text { Biological Opinion } \\ \text { CE-QUAL-W2 } & \text { Two-dimensional hydrodynamic and water-quality model } \\ \text { DEX } & \text { Dexter Lake } \\ \text { HCR } & \text { Hills Creek Lake } \\ \text { LOP } & \text { Lookout Point Lake } \\ \text { LOP-DEX } & \text { Lookout Point-Dexter Lakes } \\ \text { NFMFWR } & \text { North Fork of Middle Fork Willamette River } \\ \text { MFWR } & \text { Middle Fork Willamette River } \\ \text { RM } & \text { river mile } \\ \text { RO } & \text { regulating outlet } \\ \text { USACE } & \text { U.S. Army Corps of Engineers } \\ \text { USGS } & \text { U.S. Geological Survey }\end{array}$




\title{
Water Temperature Effects from Simulated Dam Operations and Structures in the Middle Fork Willamette River, Western Oregon
}

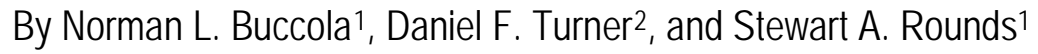

\section{Significant Findings}

Streamflow and water temperature in the Middle Fork Willamette River (MFWR), western Oregon, have been regulated and altered since the construction of Lookout Point, Dexter, and Hills Creek Dams in 1954 and 1961, respectively. Each year, summer releases from the dams typically are cooler than pre-dam conditions, with the reverse (warmer than pre-dam conditions) occurring in autumn. This pattern has been detrimental to habitat of endangered Upper Willamette River (UWR) Chinook salmon (Oncorhynchus tshawytscha) and UWR winter steelhead (O. mykiss) throughout multiple life stages. In this study, scenarios testing different dam-operation strategies and hypothetical dam-outlet structures were simulated using CE-QUAL-W2 hydrodynamic/temperature models of the MFWR system from Hills Creek Lake (HCR) to Lookout Point (LOP) and Dexter (DEX) Lakes to explore and understand the efficacy of potential flow and temperature mitigation options.

Model scenarios were run in constructed wet, normal, and dry hydrologic calendar years, and designed to minimize the effects of Hills Creek and Lookout Point Dams on river temperature by prioritizing warmer lake surface releases in May-August and cooler, deep releases in SeptemberDecember. Operational scenarios consisted of a range of modified release rate rules, relaxation of power-generation constraints, variations in the timing of refill and drawdown, and maintenance of different summer maximum lake levels at HCR and LOP. Structural scenarios included various combinations of hypothetical floating outlets near the lake surface and hypothetical new outlets at depth. Scenario results were compared to scenarios using existing operational rules that give temperature management some priority (Base), scenarios using pre-2012 operational rules that prioritized power generation over temperature management (NoBlend), and estimated temperatures from a without-dams condition (WoDams).

Results of the tested model scenarios led to the following conclusions:

- The existing outlets at Lookout Point Dam, because of the range of depths, allow for greater temperature control than the two existing outlets at Hills Creek Dam that are relatively deep.

- Temperature control at HCR through operational scenarios generally was minimal near Hills Creek Dam, but improved downstream toward the head of LOP when decreased release rates held HCR at a low lake elevation year-round.

- Inflows from unregulated streams between HCR and LOP helped to dilute the effects of HCR and achieve more natural stream temperatures before the MFWR entered LOP.

\footnotetext{
${ }^{1}$ U.S. Geological Survey.

${ }^{2}$ U.S. Army Corps of Engineers.
} 
- The relative benefit of any particular scenario depended on the location in the MFWR system used to assess the potential change, with most scenarios involving changes to Hills Creek Dam being less effective with increasing downstream distance, such as downstream of DEX.

- To achieve as much temperature control as the most successful structural scenarios, which were able to resemble without-dam conditions for part of the year, most operational scenarios had to be free of any power-generation requirements at Lookout Point Dam.

- Downstream of DEX, scenarios incorporating a hypothetical floating outlet at either HCR or LOP resulted in similar temperatures, with both scenarios causing a delay in the estimated spring Chinook egg emergence by about 9-10 days compared to base-case temperaturemanagement scenarios.

\section{Introduction}

The presence and operation of 13 dams of the Willamette Project in the Willamette River Basin, Oregon, owned and operated by the U.S. Army Corps of Engineers (USACE), have altered the natural hydrologic and thermal regime of downstream rivers in the basin (Gregory and others, 2007). Discharge from many of these dams is unseasonably warm in autumn, which contributes to high mortality rates of incubating eggs of endangered spring Chinook salmon (Oregon Department of Fish and Wildlife and National Marine Fisheries Service, 2011). Reasonable and Prudent Alternatives specified in the 2008 Biological Opinion (BiOp) require the evaluation and implementation of feasible operational and (or) structural modifications of the dams to address flow and water-quality effects of USACE projects on Upper Willamette River Chinook salmon and winter steelhead (National Marine Fisheries Service, 2008). The objective of these specified alternatives is to improve habitat conditions for anadromous fish species listed under the Endangered Species Act that will result in increased egg survival and increased survival of adult and juvenile life stages, causing increases in abundance and productivity of these fish.

Mortality rates for spring Chinook salmon at water temperatures greater than 16.0 and $17.0^{\circ} \mathrm{C}$ can exceed 50 and 98 percent, respectively (Alderdice and Velsen, 1978; Groot and Margolis, 1991; Keefer and Caudill, 2010). Water temperatures downstream of dams on the Middle Fork Willamette River (MFWR) often exceed these water temperatures from the middle of the spawning season (September) through mid-October. A previous USACE study suggested a number of anadromous fish restoration alternatives, including temperature control of water releases from Hills Creek Lake (HCR; U.S. Army Corps of Engineers, 1997). Recent efforts have focused on the feasibility of floodplain restoration downstream of Dexter Lake (DEX; Battelle Memorial Institute, 2013; TetraTech, 2013).

Controlling the temperature of water released from high-head dams is possible when water from different depths in the reservoir can be accessed and routed downstream. During spring and summer, increased surface energy fluxes tend to create a layer of warmer, less-dense water at the lake surface floating on top of colder, more-dense water at depth. By blending releases of warm surface water and deeper cold water from the lake, downstream temperatures can be controlled, at least within the limits of the release structures and the available volumes and temperatures of water in the lake. Since 2007, the USACE has blended water of different temperatures through different outlets at Detroit Dam on the North Santiam River, which is 1 of the 13 dams of the Willamette Project (Buccola and others, 2012). Temperature control also has been implemented by USACE since 2005 at Cougar Dam on the South Fork McKenzie River, another of the Willamette Project dams (Rounds, 2007). To determine the feasibility of such strategies for temperature control in the MFWR, it was necessary to construct, calibrate, and use models of the river/reservoir system to evaluate a range of potential operational and structural scenarios at Dexter, Lookout Point, and Hills Creek Dams. 
This report documents results of CE-QUAL-W2 model simulations of streamflow and water temperature in the MFWR from Hills Creek Dam downstream to the outlets of Lookout Point and Dexter Dams. Hypothetical operational and structural scenarios were imposed on three separate environmental scenarios (time frames) encompassing a wide range of meteorological and hydrologic conditions with the intention of exploring options that could achieve more-natural temperatures downstream of dams on the MFWR. Operational scenarios included variation of minimum flow releases, the timing of reservoir refill in winter/spring and reservoir drawdown in late-summer/autumn, and maintenance of different lake levels in summer. Structural scenarios included the use of various existing and hypothetical dam outlets, such as new floating or deep outlets, and applying various maximum-head and minimum power-generation constraints. Flow and meteorological conditions encompassed a wide range of measurements drawn from recent years (2002-08). Results were compared to existing as well as estimated without-dams conditions.

\section{Study Area}

The Middle Fork Willamette River is located in the southern, most upstream reaches of the Willamette River Basin in western Oregon (fig. 1). The river generally runs northwesterly and flows through or near the communities of Oakridge, Westfir, Dexter, and Lowell before joining with the Coast Fork Willamette River to form the Willamette River near Eugene and Springfield, Oregon. Major tributaries of consideration include Hills Creek, Salt Creek, Salmon Creek, the North Fork of the Middle Fork Willamette River ([NFMFWR)], and Fall Creek. The river is impounded by three dams (in downstream order)—Hills Creek Dam, Lookout Point Dam, and Dexter Dam (fig. 1). 


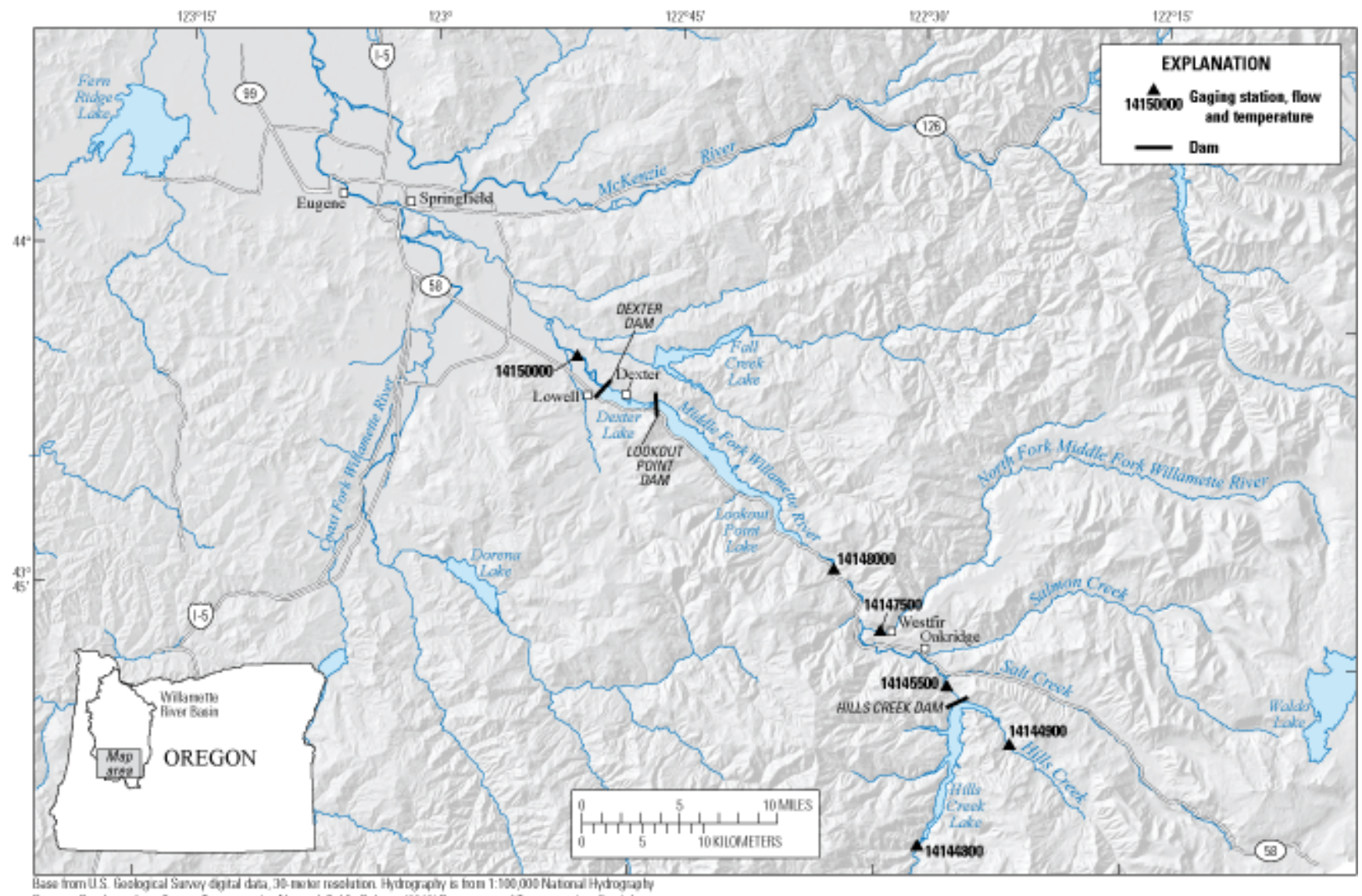

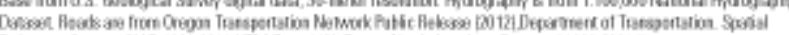

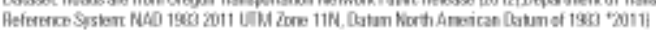

Figure 1. Map showing Middle Fork Willamette River study area, Oregon (reproduced from Buccola and others, 2013).

Hills Creek Dam is an earthen dam that is $304 \mathrm{ft}(92.7 \mathrm{~m})$ in height; it was completed in 1961. HCR impounds 355,500 acre-ft $\left(4.39 \times 10^{8} \mathrm{~m}^{3}\right)$ of water at a full pool elevation of $1,543 \mathrm{ft}(470.3 \mathrm{~m})$ (fig. 2). Lookout Point Dam is an earth and gravel-fill dam with a concrete gated spillway; the dam is $276 \mathrm{ft}$ (84 m) in height and was completed in 1954. Lookout Point Lake (LOP) is the largest reservoir in the Willamette River Basin, impounding 455,800 acre-ft $\left(5.89 \times 10^{8} \mathrm{~m}^{3}\right)$ of water at a full pool elevation of $929 \mathrm{ft}$ (283.2 m). Dexter Dam, also an earth and gravel-fill dam with a concrete gated spillway, is 93 $\mathrm{ft}(28.3 \mathrm{~m})$ in height and was completed in 1954. Dexter Lake impounds 27,500 acre-ft $\left(3.39 \times 10^{7} \mathrm{~m}^{3}\right)$ of water at a full pool elevation of $695 \mathrm{ft}(211.8 \mathrm{~m})$. Dexter Dam is a re-regulating dam that buffers the sometimes irregular flows released from Lookout Point Dam. These three dams were constructed for multiple purposes, including flood-damage minimization, hydropower, and recreation, as well as downstream flow augmentation during the low-flow summer season. 


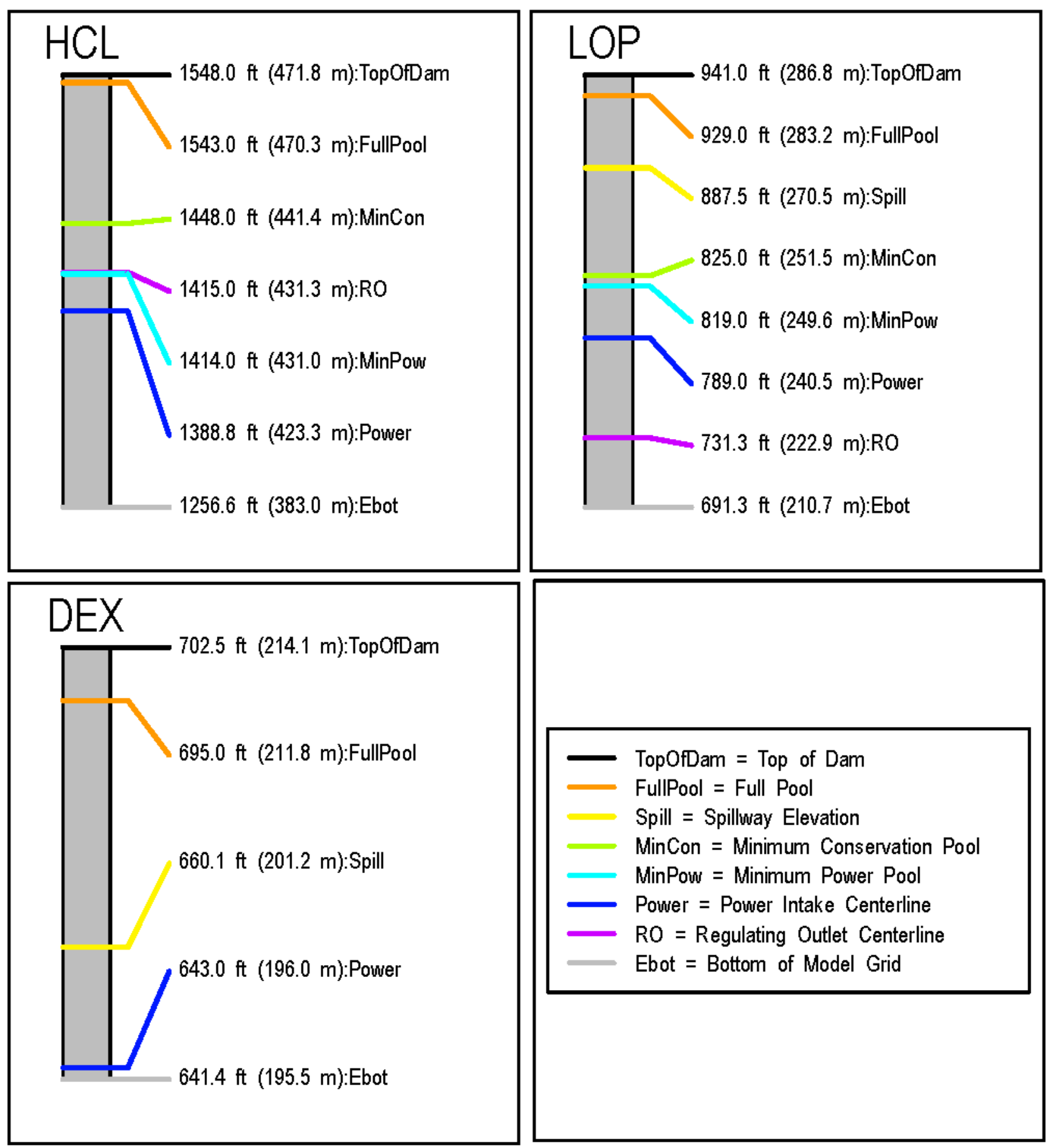

Figure 2. Diagrams showing elevations of operational goals and structures for Hills Creek, Lookout Point, and Dexter Dams, Oregon (reproduced from Buccola and others, 2013). Elevations are referenced to the National Geodetic Vertical Datum of 1929). 


\section{Methods and Data}

\section{Model Description}

CE-QUAL-W2 is a two-dimensional, longitudinal-vertical, hydrodynamic and water-quality model constructed and maintained by USACE and Portland State University (Cole and Wells, 2011). CE-QUAL-W2 models of Hills Creek, Lookout Point, and Dexter Lakes on the MFWR have been developed to help manage dam releases, understand the effects of the dams on stream temperatures, and plan strategies that should result in water temperatures less detrimental to Chinook salmon and winter steelhead populations (Buccola and others, 2013). The model assumes lateral homogeneity within each cell of the grid, and, therefore, is best suited for relatively narrow water bodies that tend to stratify, resulting in predominantly longitudinal and vertical water-quality gradients. The CE-QUAL-W2 model has been applied successfully to other reservoirs in the Willamette River Basin, such as Detroit Lake, and was used to evaluate the effects of modifications to dam operations and outlet structures (Buccola and others, 2012).

The MFWR and reservoir models were developed using a customized version of the CE-QUALW2 model, version 3.7, which allows for blending of outflows from multiple dam outlets to meet a specified temperature target (Rounds and Buccola, 2015). Three CE-QUAL-W2 models were used in this study:

1. HCR,

2. The riverine section of the MFWR between Hills Creek Dam and LOP, and

3. Lookout Point and Dexter Lakes [LOP-DEX].

Developed and calibrated under measured conditions in 2002, 2006, 2008, and 2011, these models were documented by Buccola and others (2013) and used without modification.

\section{Boundary Conditions}

\section{Environmental Scenarios}

Three distinctly different environmental forcing scenarios, encompassing streamflow input, temperature inflow, and weather conditions, were developed to provide a range of conditions imposed on the models for evaluating temperature-management options within the MFWR Basin. To ensure that the streamflow, water temperature, and meteorological datasets used to drive the models were consistent with each other, the simplest approach was to use historical datasets that represented a wide range of possible hydrologic conditions, including wet (about 75th percentile), normal (about median), and dry (about 25th percentile) conditions. Recent time frames (2002, 2006, 2008) as selected by Buccola and others (2013) were used for this study. Measured data from 2006 and 2008 were split on October 19 and concatenated to each other to better represent the normal (2006 data prior to October 19, with 2008 data after October 19) and wet scenarios (fig. 3, table 1). Relatively dry conditions were represented with data from 2002. Values shown in figure 3 represent 10-day average streamflows, and are not exact representations of the percentiles in table 1. 


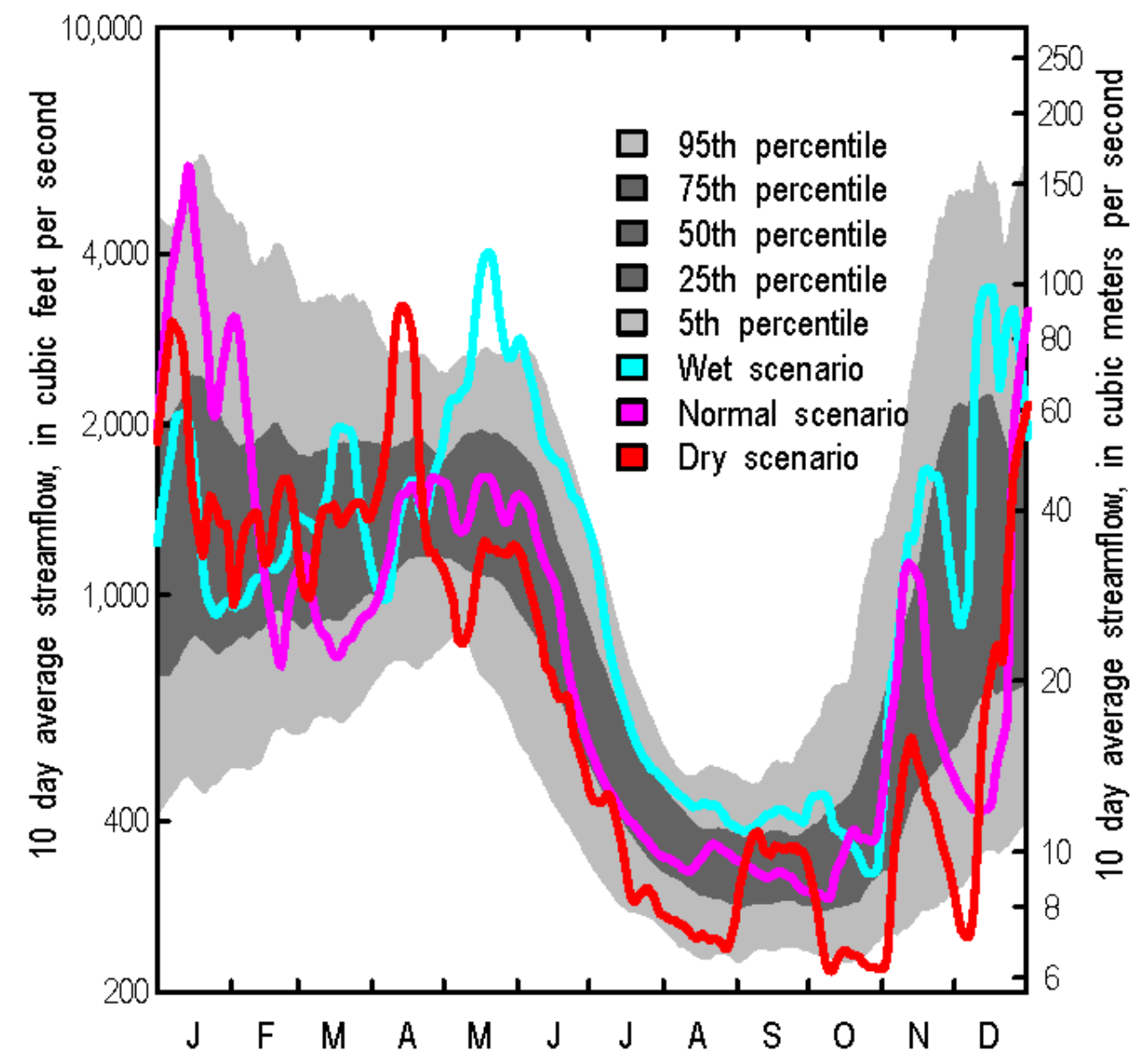

Figure 3. Graph showing total streamflow into Hills Creek Lake, Oregon, under environmental scenarios along with historical percentiles for 1936-2011.

Table 1. Description of environmental scenarios and percentiles of inflows for Hills Creek Lake, Oregon, 19352011.

\begin{tabular}{l|ccc|ccc}
\hline \multirow{2}{*}{$\begin{array}{c}\text { Environmental forcing } \\
\text { scenarios }\end{array}$} & \multicolumn{3}{|c|}{ Measured time frame } & \multicolumn{3}{c}{ Percentile of historical flow (1935-2011) } \\
\cline { 2 - 7 } & $\begin{array}{c}\text { Springl } \\
\text { summer }\end{array}$ & $\begin{array}{c}\text { Autumnl } \\
\text { winter }\end{array}$ & $\begin{array}{c}\text { Concatenate } \\
\text { date } \\
\text { (month-day) }\end{array}$ & $\begin{array}{c}\text { January 1- } \\
\text { October 18 }\end{array}$ & $\begin{array}{c}\text { October 19- } \\
\text { December 31 }\end{array}$ & Full year \\
\hline Wet & 2008 & 2006 & $10-19$ & 65 & 92 & 76 \\
Normal & 2006 & 2008 & $10-19$ & 55 & 10 & 42 \\
Dry & 2002 & 2002 & - & 40 & 3 & 17 \\
\hline
\end{tabular}




\section{Hydrologic and Meteorological Data}

CE-QUAL-W2 requires time series inputs of streamflow, water temperature, and six meteorological parameters: air temperature, dew-point temperature, wind speed, wind direction, cloud cover, and solar radiation. Sources and construction of the meteorological and hydrologic input datasets for the models used in this study were documented by Buccola and others (2013).

\section{Outflow Estimation}

The total release rates (outflows) from HCR and LOP-DEX were set to adhere to the following conditions:

1. Releases from Hills Creek Dam should meet a year-round minimum flow requirement of 400 $\mathrm{ft}^{3}$ /s, as specified by the BiOp (National Marine Fisheries Service, 2008, table 2-10).

2. Releases from Dexter Dam, and consequently Lookout Point Dam, should meet a year-round minimum flow requirement of $1,200 \mathrm{ft}^{3} / \mathrm{s}\left(34 \mathrm{~m}^{3} / \mathrm{s}\right)$ and a maximum flow requirement of 3,500 $\mathrm{ft}^{3} / \mathrm{s}\left(99 \mathrm{~m}^{3} / \mathrm{s}\right.$ ) (September 1-October 15) similar to those as specified by the BiOp (National Marine Fisheries Service, 2008, table 2-10). Exceptions to this rule were established for scenarios where minimum release flows of 400 and $440 \mathrm{ft}^{3} / \mathrm{s}\left(11\right.$ and $\left.13 \mathrm{~m}^{3} / \mathrm{s}\right)$ were used.

3. Computed water levels in Hills Creek and Lookout Point Lakes should not exceed the reservoir rule curve (the operational target for the lake water-surface elevation throughout the year) for more than 5 days when the lake is at full-pool elevation.

4. Use of the Lookout Point Dam power penstock outlets for "power peaking” was assumed to occur such that releases were made during the hours of 0500-1200 and 1400-2200 each day, and releases outside those time windows might be zero ${ }^{3}$.

5. The water-surface elevation of DEX should be between 685 and $695 \mathrm{ft}$ (209 and $212 \mathrm{~m}$ ) yearround.

6. Release rates from HCR and LOP-DEX should not exceed 8,000 and 15,000 $\mathrm{ft}^{3} / \mathrm{s}$ (227 and 425 $\mathrm{m}^{3} / \mathrm{s}$ ), respectively, at any time.

\section{Without-Dam Water Temperature Estimation}

Without-dam water temperatures for the MFWR were estimated at two locations-Hills Creek Dam (river mile [RM] 232.5) and Dexter Dam (RM 204) — to serve as a reference for model simulation results and to help develop temperature targets for the CE-QUAL-W2 models (described further in section, “Operational Temperature Targets”). Without-dam temperature estimates were computed using a simple mass and energy balance approach combined with a nominal downstream warming rate applied during summer, following methods documented by Rounds (2010).

\footnotetext{
${ }^{3}$ In reality, "power peaking” pertains only to the power penstock outlets; however, to enable the blending subroutine in CE-QUAL-W2 to determine the optimum balance of releases to meet downstream temperature targets, all outlets had to be placed on this flow schedule and used concurrently. Such concurrent releases might not represent actual future dam operations, and the timing of releases (concurrent compared to staggered) can have an effect on daily temperature variations immediately downstream of Lookout Point Dam but not likely downstream of Dexter Dam. The power peaking schedule was used only on days when the daily average release rate was less than $2,472 \mathrm{ft}^{3} / \mathrm{s}$ $\left(70 \mathrm{~m}^{3} / \mathrm{s}\right)$. This rule helped to simplify the simulated maintenance of a stable water level in the downstream DEX model and came close to the way Lookout Point Dam is operated during large storm events.
} 


\section{Hills Creek Dam}

Without-dam temperatures at the Hills Creek Dam site were derived using measured or estimated water temperatures from sites on Hills Creek and the MFWR upstream of HCR. A maximum downstream warming rate of $0.11^{\circ} \mathrm{C} / \mathrm{mi}$ was applied over the distances from the measurement sites to Hills Creek Dam. For the modeled periods, these distances were $4.2 \mathrm{mi}(6.8 \mathrm{~km})$ on Hills Creek (U.S. Geological Survey [USGS] streamgage 14144900) and $8.5 \mathrm{mi}(13.7 \mathrm{~km})$ on the MFWR (USGS streamgage 14144800). From November 1 to April 13, or any time of year when water temperatures were less than $10^{\circ} \mathrm{C}$, no instream warming adjustments were made. From April 14 to October 31, a downstream warming rate was applied as a function of the measured or estimated upstream water temperature, based on an assumption that warmer water was an indication of conditions that were favorable for some warming as water moved from the measurement location to the dam site. The maximum downstream warming rate of $0.11^{\circ} \mathrm{C} / \mathrm{mi}$ was based on historical data (Moore, 1964, 1967). Upstream water temperatures less than $16{ }^{\circ} \mathrm{C}$ but greater than $10^{\circ} \mathrm{C}$ were increased to account for some downstream warming, but using a rate that was less than the maximum rate of $0.11^{\circ} \mathrm{C} / \mathrm{mi}$, using the following linear interpolation:

$$
\mathrm{T}=\mathrm{T}_{\text {est }}+0.11\left({ }^{\circ} \mathrm{C} / \mathrm{mi}\right) \times \text { distance }(\mathrm{mi})\left(\mathrm{T}_{\text {est }}-10.0\right) \div(16.0-10.0), \quad 10.0 \leq \mathrm{T}_{\text {est }} \leq 16.0
$$

where

$\mathrm{T}_{\text {est }}$ is upstream measured or estimated water temperature, in degrees Celsius and

$\mathrm{T}$ is downstream water temperature estimate in degrees Celsius.

Water temperatures from the MFWR and Hills Creek streamgages that incorporated warming were then weighted and averaged based on respective upstream drainage areas (59.9 $\mathrm{mi}^{2}$ for Hills Creek, $330 \mathrm{mi}^{2}$ for the MFWR) as follows:

$$
\mathrm{T}_{\text {mix }}=\left(\mathrm{A}_{\mathrm{MFW}} \mathrm{T}_{\mathrm{MFW}}+\mathrm{A}_{\mathrm{HC}} \mathrm{T}_{\mathrm{HC}}\right) /\left(\mathrm{A}_{\mathrm{MFW}}+\mathrm{A}_{\mathrm{HC}}\right)
$$

where

$\mathrm{T}_{\text {mix }}$ is mixed water temperature estimate, in degrees Celsius,

AMFW is upstream watershed area at MFWR streamgage 14144800, in square miles,

TMFW is downstream water temperature estimate derived from MFWR water temperature at streamgage 14144800, in degrees Celsius,

AHC is upstream watershed area at Hills Creek streamgage 14144900 in square miles, and

THC is downstream water temperature estimate derived from Hills Creek water temperature at streamgage 14144900, in degrees Celsius.

The drainage-area weighting approach in equation 2 is similar to the application of an energy balance using streamflows at the two upstream sites as the weighting factors because a drainage-area ratio technique often is used to estimate streamflow data. If such a drainage-area ratio technique were used to estimate streamflow at one site based on measured streamflow at the second site, then the streamflow weighting in an energy balance would be equivalent to the drainage-area weighting used in this method. 


\section{Dexter Dam}

Estimating without-dams water temperatures at the site of Dexter Dam was done in two ways. For periods simulated by the models in this study (2002, 2006, 2008) and, therefore, covering the environmental scenarios to be modeled, the MFWR model was used to simulate water temperatures at the head of LOP by assigning (1) without-dam water temperatures at Hills Creek Dam, and (2) the summation of total inflows to HCR under each environmental scenario as the inflow boundary conditions. Next, the simulated water temperatures from the MFWR model at the head of LOP were warmed for 14.7 mi using equation 1, to represent the potential warming that might occur as water moved downstream to Dexter Dam.

For periods not simulated with the MFWR model, without-dam water temperatures at Dexter Dam were estimated using an energy balance method similar to that used to compute without-dam water temperatures at Hills Creek Dam, following the method of Rounds (2010). The energy balance was constructed using upstream temperature and flow data from the NFMFWR near Oakridge, Oregon (USGS streamgage 14147500, 5.0 river miles upstream of LOP), and from the without-dam temperature calculation at Hills Creek Dam (13.8 miles upstream of LOP). Without-dam streamflow conditions at Hills Creek Dam were estimated as the unregulated inflow dataset to HCR and were obtained from the USACE data query Web site (dataset “HCR.Flow-In.Ave. 1Day.1Day.Best” [U.S. Army Corps of Engineers, 2015]). Few flow or temperature data were available for Salt and Salmon Creeks, tributaries to MFWR downstream of HCR and upstream of LOP. It was assumed, therefore, that water temperatures at the mouths of these tributaries were similar to the NFMFWR temperature measurements and the HCR without-dam temperatures, such that these tributaries could be omitted from the analysis.

Applying equation 1 when needed, the NFMFWR measured temperatures and Hills Creek Dam without-dams temperatures were warmed downstream to the head of LOP, then mixed using a version of equation 2, only substituting flow data in place of the upstream watershed areas. The mixed water from the head of LOP and then was warmed downstream using equation 1 to the location of the USGS streamgage on the MFWR downstream of Dexter Dam (USGS streamgage 14150000). This streamgage was used as the location for without-dam temperature estimates because it is a potential reference point for real-time feedback for upstream dam operations.

\section{Operational Temperature Targets}

Operational water temperature targets were developed for the MFWR and for use with the CEQUAL-W2 models to optimize dam release temperatures under each environmental scenario. Factors considered in developing the operational water temperature targets included:

1. Biological threshold temperatures,

2. Life stages of target fish species,

3. Seasonal temperature patterns and magnitudes, and

4. Seasonal operational feasibility.

It was assumed that the long-term trends of without-dam calculations (based on available flow and temperature data upstream of the dams) were reasonable surrogates for natural conditions given that most of the watershed is forested and managed by the U.S. Forest Service. Separate temperature targets were developed for Hills Creek and Dexter Dams to optimize the release temperatures and operations of the Hills Creek and Lookout Point Lake models, respectively. Temperature control at Dexter Dam was assumed to be minimal compared to Lookout Point Dam and was ignored for this study because of the relatively shallow depth and short residence time of water in DEX compared to LOP. 
The without-dams temperature calculations indicated that the without-dam daily mean temperatures at Hills Creek Dam between 1956 and 2014 typically peaked in late July and ranged at that time from 13.8 to $20.6{ }^{\circ} \mathrm{C}$ with a mean of $16.6^{\circ} \mathrm{C}$ ("Without-Dams Range" in fig. 4). The magnitudes and patterns of the without-dam temperatures are similar to the magnitudes and patterns of temperatures measured at the NFMFWR near its mouth, an unregulated system. Both basins have their headwaters in the High Cascades and are similar in size (392 $\mathrm{mi}^{2}$ for the MFWR upstream of Hills Creek Dam, and $246 \mathrm{mi}^{2}$ upstream of the NFMFWR streamgage). The similarity in temperatures from these two sites provides additional justification for using the without-dam temperatures as a surrogate for natural or close-to-natural temperatures.

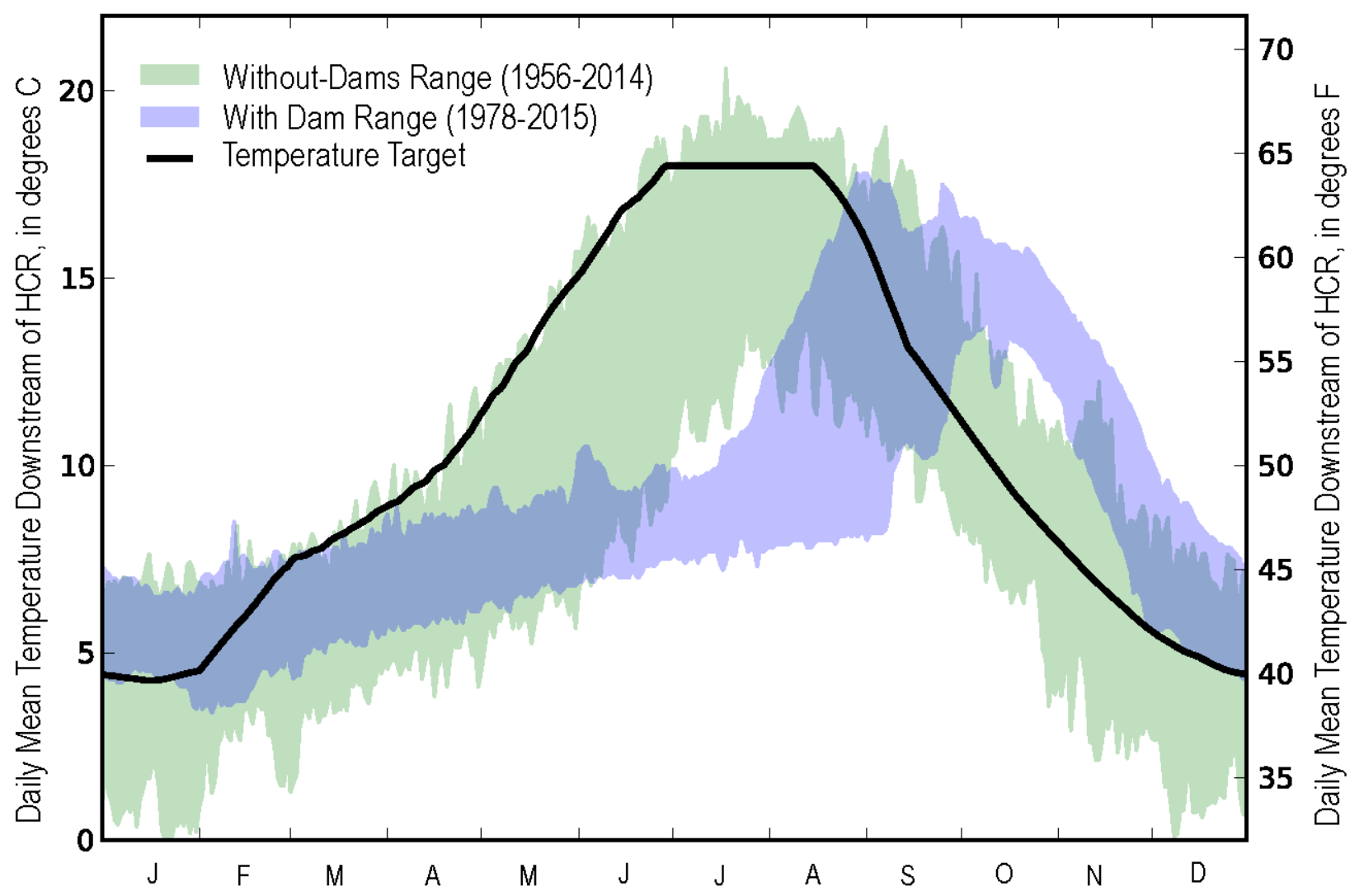

Figure 4. Graph showing operational temperature target for Hills Creek Lake, showing without-dams daily mean temperature estimates for 1956-2014, and with-dam daily mean temperature measurements, Middle Fork Willamette River, Oregon, 1978-2015. 
For the streamgage downstream of Dexter Dam, the annual maximum without-dam daily mean temperatures between 2001 and 2014 typically occurred in early August and ranged from about 18.0 to $21.1^{\circ} \mathrm{C}$ with a mean of $19.4^{\circ} \mathrm{C}$ (fig. 5). The magnitudes and patterns of the without-dams temperatures are similar to the magnitudes and patterns of monthly mean temperatures measured prior to construction of the dams from 1950 to 1953 (August temperatures ranged from 13.9 to $21.1^{\circ} \mathrm{C}$ with a mean of 17.8 ${ }^{\circ} \mathrm{C}$ [Moore, 1964]). This temperature similarity provides increased confidence for the use of the without-dams temperatures as a surrogate for natural or close-to-natural temperatures.

The operational temperature target is a critical input to the CE-QUAL-W2 models, and potentially a guide for dam operators, to determine the amount of water released through different dam outlets, but within system constraints. The goals of the operational temperature target are to guide dam operations so that (1) warm water is evacuated from the reservoirs during the warmest parts of summer, (2) downstream stream temperatures do not exceed a specified numeric target for the protection of endangered fish species in summer, and (3) cold water from the reservoir is discharged during the spawning and incubation period in late summer and autumn. The targets are daily mean temperatures specified for temperature gages at two locations—-downstream of Hills Creek and Dexter Dams.

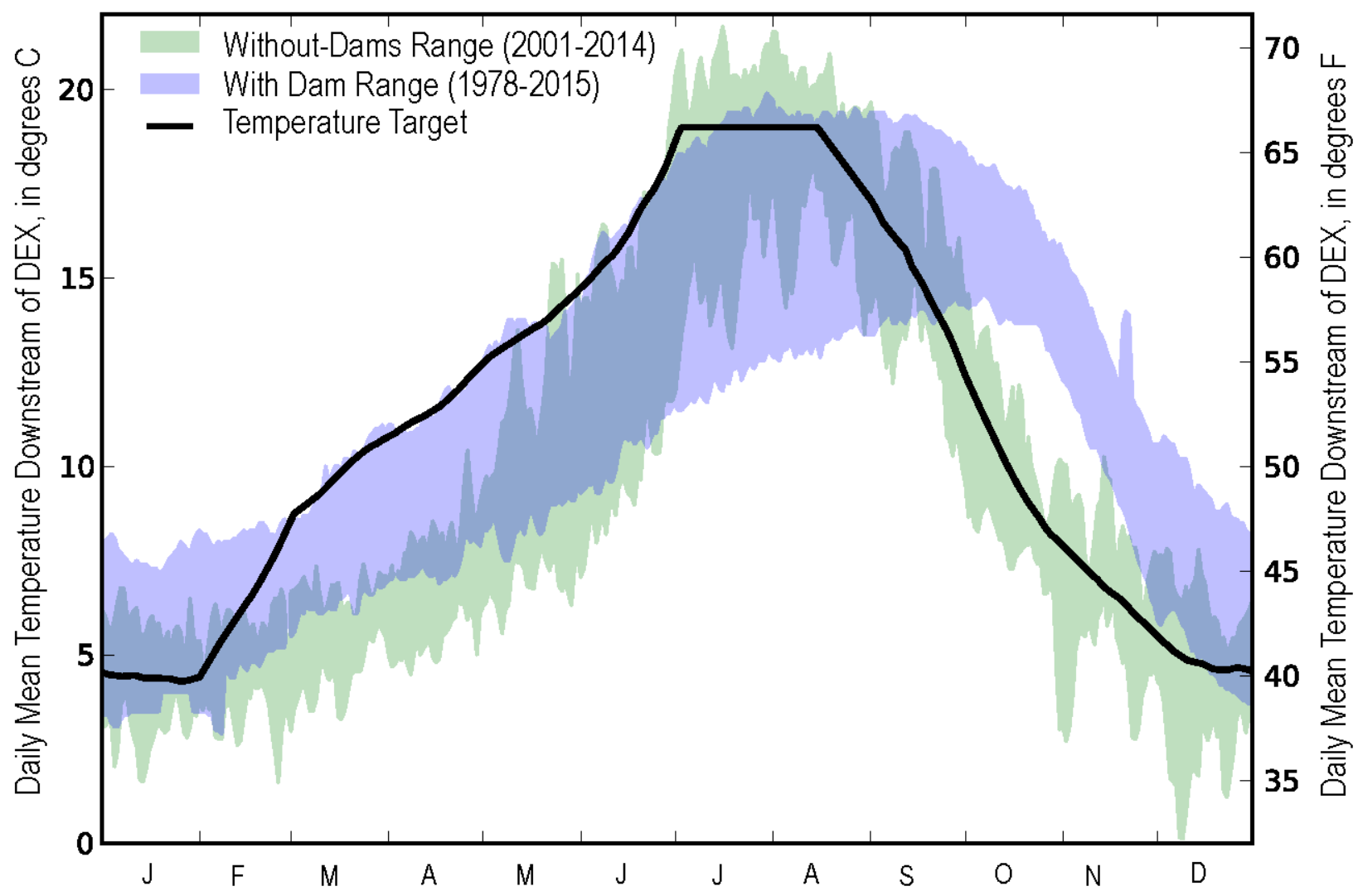

Figure 5. Graph showing operational temperature target downstream of Dexter Dam, showing without-dams daily mean temperature estimates for 2001-2014, and with-dam daily mean temperature measurements, Middle Fork Willamette River, Oregon, 1978-2015. 
For the salmonid rearing period (February 1-August 31; see National Marine Fisheries Service, 2008, table 2-10), the targets are based on (1) the 30-day running average of the maximum daily mean without-dam or historical temperature for a given day of the year, and (2) a maximum daily mean temperature of $18.0^{\circ} \mathrm{C}\left(64.4^{\circ} \mathrm{F}\right)$ downstream of Hills Creek Dam and $19.0^{\circ} \mathrm{C}\left(66.2^{\circ} \mathrm{F}\right)$ downstream of Dexter Dam (figs. 4-5). The spawning and incubation period just downstream of Hills Creek Dam was assumed to be identical to the spawning and incubation period designated for the river reach downstream of Dexter Dam in the Willamette River BiOp (February-August 31; see National Marine Fisheries Service, 2008, table 2-10).

For the spawning and incubation period (September 1-January 31), the targets are based on (1) the 30-day running average of the daily mean without-dam temperatures, and (2) a maximum daily mean temperature of $15.6^{\circ} \mathrm{C}\left(60.0^{\circ} \mathrm{F}\right)$. A 30-day transition period was established at the beginning and end of the rearing period to minimize abrupt changes in the target temperatures (figs. 4-5).

\section{Results and Discussion}

Many scenarios were developed to test the potential downstream effects of altered rule curves, hydropower demands, minimum summer streamflow requirements, and hypothetical structures at Hills Creek, Lookout Point, and Dexter Dams. As scenarios were developed, emphasis was placed on the goal achieving without-dam water temperatures downstream of the dams while evaluating the spectrum of potential temperature-management options. Aside from hydropower production constraints, some flexibility to access and release water with a range of temperatures currently exists at Lookout Point Dam with its spillway, power, and regulating outlets (ROs) at a range of depths in the lake. Releases from Hills Creek Dam are currently limited to its two relatively deep outlets: RO and power (fig. 2).

Operational scenarios consisting of various year-round minimum release rates and lake elevation rules for specific times of the year (operational scenario groups in table 2) were applied in combination with various scenarios governing existing and hypothetical outlet structures at Hills Creek and Lookout Point Dams (structural scenario groups in table 3). For example, Base scenarios represented existing operations at the dams, whereas HcrSpillwayWs1510 and HcrWs1448 showed the effects of lower HCR surface elevations. A decrease in minimum year-round release rates at LOP under LopDelayRefill and LopWs825 scenarios allowed lower lake elevations for some times of the year.

Some scenarios included hypothetical structures floating near the surface or located deep in the lake. The model parameters defining these structures were based on those developed during the calibration of the models for existing structures at the dams. For example, hypothetical floating versions of existing outlets were meant to mimic the size and characteristics of existing outlets, but were situated at a different depth, such as a floating outlet at Hills Creek Dam with characteristics similar to its RO, or a floating outlet at Lookout Point Dam with characteristics similar to its spillway (table 3). Structural scenarios at Hills Creek Dam ranged from existing structures (Base) to including the emergency spillway (HcrSpillway) or a hypothetical floating surface and deeper outlet (HcrFloat_Pow1300). At LOP, a hypothetical floating surface withdrawal structure was simulated in the LopFloat structural scenario. Some operational/structural scenarios are highlighted in the main body of this report, whereas others that achieved similar results are not discussed in detail, but are included in summary tables 5-7 and figures 10, 11, and 15-18. All scenarios were run for each of three environmental scenarios (dry, normal, and wet). 
Table 2. Operational model scenario groups and associated refill, drawdown, and minimum lake elevation, Hills Creek and Lookout Point Dams, Oregon.

[ft, foot; $\mathrm{ft}^{3} / \mathrm{s}$, cubic foot per second]

\begin{tabular}{|c|c|c|c|c|}
\hline $\begin{array}{c}\text { Operational scenario } \\
\text { groups }\end{array}$ & $\begin{array}{c}\text { Year-round } \\
\text { minimum } \\
\text { release rates } \\
\left(\mathrm{ft}^{3} / \mathrm{s}\right)\end{array}$ & $\begin{array}{l}\text { Date refill } \\
\text { begins }\end{array}$ & $\begin{array}{l}\text { Date drawdown } \\
\text { begins }\end{array}$ & $\begin{array}{l}\text { Maximum lake } \\
\text { elevation } \\
\text { (ft) }\end{array}$ \\
\hline \multicolumn{5}{|c|}{ Hills Creek Dam operational scenarios } \\
\hline Base & 400 & February 1 & September 1 & 1,541 \\
\hline HcrSpillwayWs1510 & 400 & February 1 & September 1 & 1,510 \\
\hline HcrWs1448 & 400 & No refill & No refill & 1,448 \\
\hline \multicolumn{5}{|c|}{ Lookout Point Lake and Dam operational scenarios } \\
\hline Base & 1,200 & February 1 & September 1 & 926 \\
\hline LopDelayRefill & 400 & May 1 & September 1 & 926 \\
\hline LopWs825 & 440 & No refill & No refill & 825 \\
\hline
\end{tabular}

Table 3. Structural model scenarios and associated model parameter settings, Hills Creek and Lookout Point Dams, Oregon.

[CE-QUAL-W2 model parameter: STR ELEV and STR WIDTH are parameters in the w2_con.npt file, PRIORITY, MINFRAC, DEPTH, and MAXHEAD are parameters in the w2_selective.npt file. Important dam elevations are shown in figure 2. Abbreviations: m, meter; na, not applicable; RO, regulating outlet]

\begin{tabular}{|c|c|c|c|c|c|c|c|}
\hline \multirow{2}{*}{$\begin{array}{l}\text { Structural scenario } \\
\text { groups }\end{array}$} & \multirow{2}{*}{$\begin{array}{l}\text { Structure } \\
\text { name }\end{array}$} & \multicolumn{6}{|c|}{ CE-QUAL-W2 model parameter } \\
\hline & & $\begin{array}{l}\text { STR ELEV } \\
(\mathrm{m})\end{array}$ & $\begin{array}{l}\text { STR WIDTH } \\
\text { (m) }\end{array}$ & PRIORITY & MINFRAC & $\begin{array}{l}\text { DEPTH } \\
(\mathrm{m})\end{array}$ & $\begin{array}{l}\text { MAXHEAD } \\
(\mathrm{m})\end{array}$ \\
\hline \multicolumn{8}{|c|}{ Hills Creek Dam structural scenarios } \\
\hline \multirow[t]{2}{*}{ Base } & RO & 431.3 & 6.0 & 2 & 0.0 & 0.0 & 0.0 \\
\hline & Power & 423.3 & 5.8 & 1 & 0.4 & 0.0 & 0.0 \\
\hline NoBlend & Power & 423.3 & 5.8 & & & na & \\
\hline \multirow[t]{3}{*}{ HcrSpillway } & Spillway & 455.8 & 6.0 & 2 & 0.0 & 0.0 & 0.0 \\
\hline & RO & 431.3 & 6.0 & 2 & 0.0 & 0.0 & 0.0 \\
\hline & Power & 423.3 & 5.8 & 1 & 0.4 & 0.0 & 0.0 \\
\hline \multirow[t]{3}{*}{ HcrFloat_Pow1300 } & Floating outlet & 431.3 & 6.0 & 2 & 0.0 & 1.0 & 0.0 \\
\hline & Power & 423.3 & 5.8 & 1 & 0.0 & 0.0 & 0.0 \\
\hline & Lower outlet & 396.2 & 5.8 & 2 & 0.0 & 0.0 & 0.0 \\
\hline \multicolumn{8}{|c|}{ Lookout Point Dam structural scenarios } \\
\hline \multirow[t]{3}{*}{ Base } & Spillway & 270.5 & 75.7 & 2 & 0.0 & 0.0 & 0.0 \\
\hline & Power & 240.5 & 19.0 & 1 & 0.4 & 0.0 & 0.0 \\
\hline & RO & 222.9 & 4.0 & 2 & 0.0 & 0.0 & 51.4 \\
\hline NoBlend & Power & 240.5 & 19.0 & & & na & \\
\hline \multirow[t]{3}{*}{ LopFloat } & Floating outlet & 270.5 & 75.7 & 2 & 0.0 & 1.0 & 0.0 \\
\hline & Power & 240.5 & 19.0 & 1 & 0.0 & 0.0 & 0.0 \\
\hline & RO & 222.9 & 4.0 & 2 & 0.0 & 0.0 & 51.4 \\
\hline
\end{tabular}


Results from the operational and structural model scenarios were compared to Base conditions that represent current operational guidelines in place at Hills Creek, Lookout Point, and Dexter Dams in each of the hydrologic calendar-year scenarios. These Base reference conditions then were applied with the models using a set of temperature targets to determine the extent to which current operations and structures at Hills Creek and Lookout Point Dams would be able to meet those temperature targets under the different environmental (dry, normal, and wet) scenarios. The relatively shallow depth, limited coldwater storage, and short residence time in DEX limited the extent to which temperature management could be applied at Dexter Dam.

\section{Simulated Outflows and Lake Levels}

\section{Operational Scenarios}

Before comparing simulated outflow temperatures, it is helpful to compare simulated release rates and lake-surface elevations in each of the operational scenarios (table 2), as timing of releases and lake level can contribute greatly to the resulting temperature regime in the lake and downstream. Simulated release rates averaged across wet, normal, and dry environmental scenarios downstream of HCR and DEX showed substantial variation among the operational scenarios to attain different lake levels or to use modified refill or drawdown timetables (fig. 6). Base scenarios specified total release rates that satisfied the USACE rule curves and minimum flow requirements in place at Hills Creek and Lookout Point Dams. Scenarios HcrSpillwayWs1510 and HcrWs1448 were developed to examine the potential effects of two lower lake elevations (just above the emergency spillway crest [1,510 ft], and minimum conservation pool [1,448 ft]) at HCR with reduced release rates through the summer months. The emergency spillway at Hills Creek Dam cannot currently be used and, therefore, represents both an operational and a structural scenario. These operational scenarios generally resulted in higher HCR and DEX release rates during spring and lower release rates in autumn compared to Base operations (fig. 6). Minimum flow releases had to be decreased substantially in summer at Dexter Dam under the LopDelayRefill scenario in an attempt to fill LOP under a delayed refill schedule.

The range of simulated lake levels over wet, normal, and dry environmental scenarios at HCR and LOP showed that different water levels in the lakes generally could be achieved through modified release rates, but that some variation in lake level among wet and dry years had to be expected (fig. 7). In most environmental scenarios, Base scenarios resulted in simulated lake levels that closely matched the USACE rule curve during spring and early summer, and that were below the rule curve during late summer when minimum release rates were placed in higher priority over lake elevation requirements (fig. 7). Both the LopDelayRefill and LopWs825 scenarios altered release rates at Lookout Point Dam to maintain a lower level in LOP at the minimum conservation pool (825 ft) for February-May or yearround, respectively (fig. 7B). 

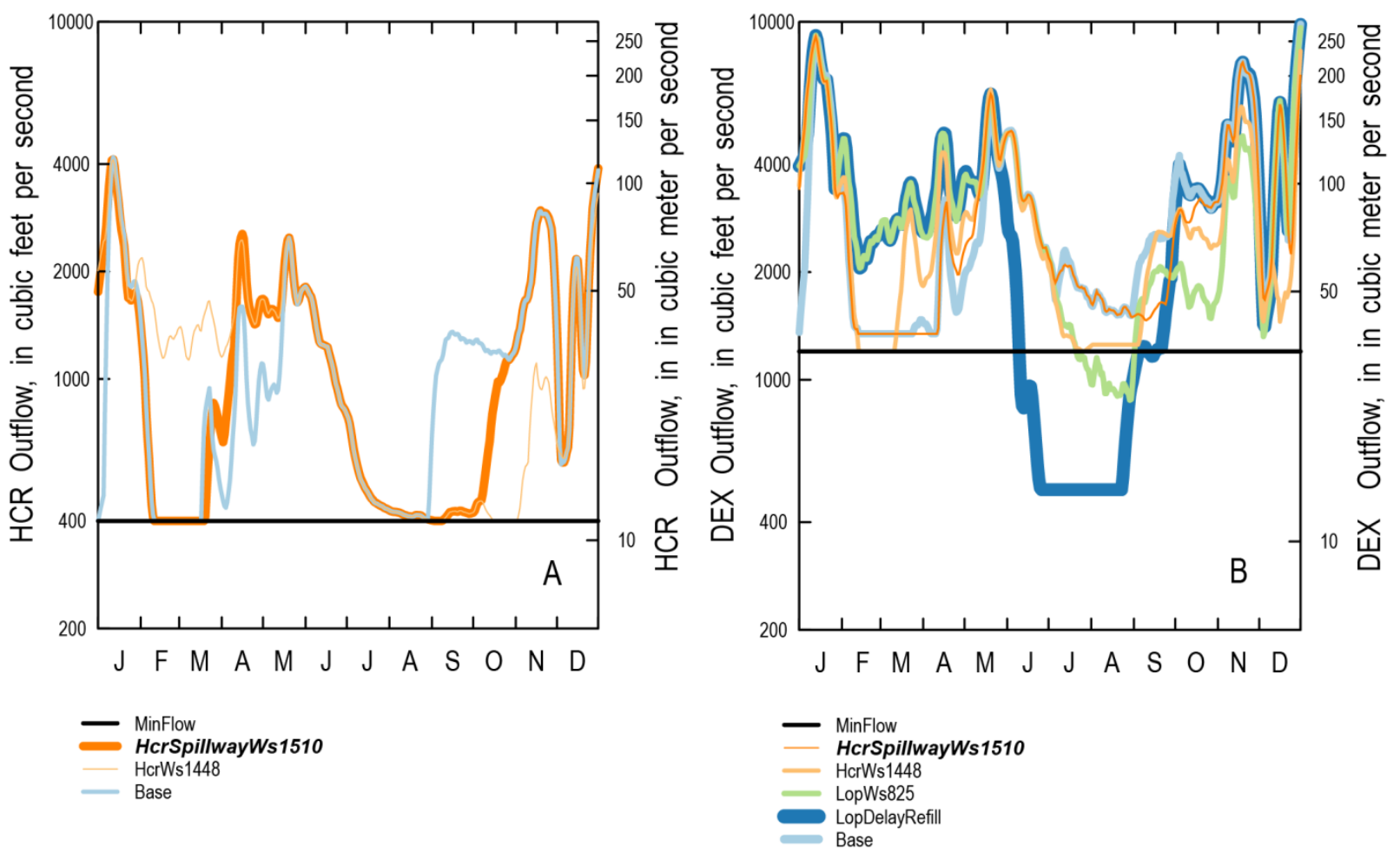

Figure 6. Graphs showing simulated release rates from (A) Hills Creek Lake (HCR), and (B) Dexter Lake (DEX), Oregon, under various operational scenarios and averaged across wet, normal, and dry environmental scenarios, January-December. See table 2 for explanation of scenario names. MinFlow shows the current minimum flow requirement specified by the 2008 Willamette River Biological Opinion. 

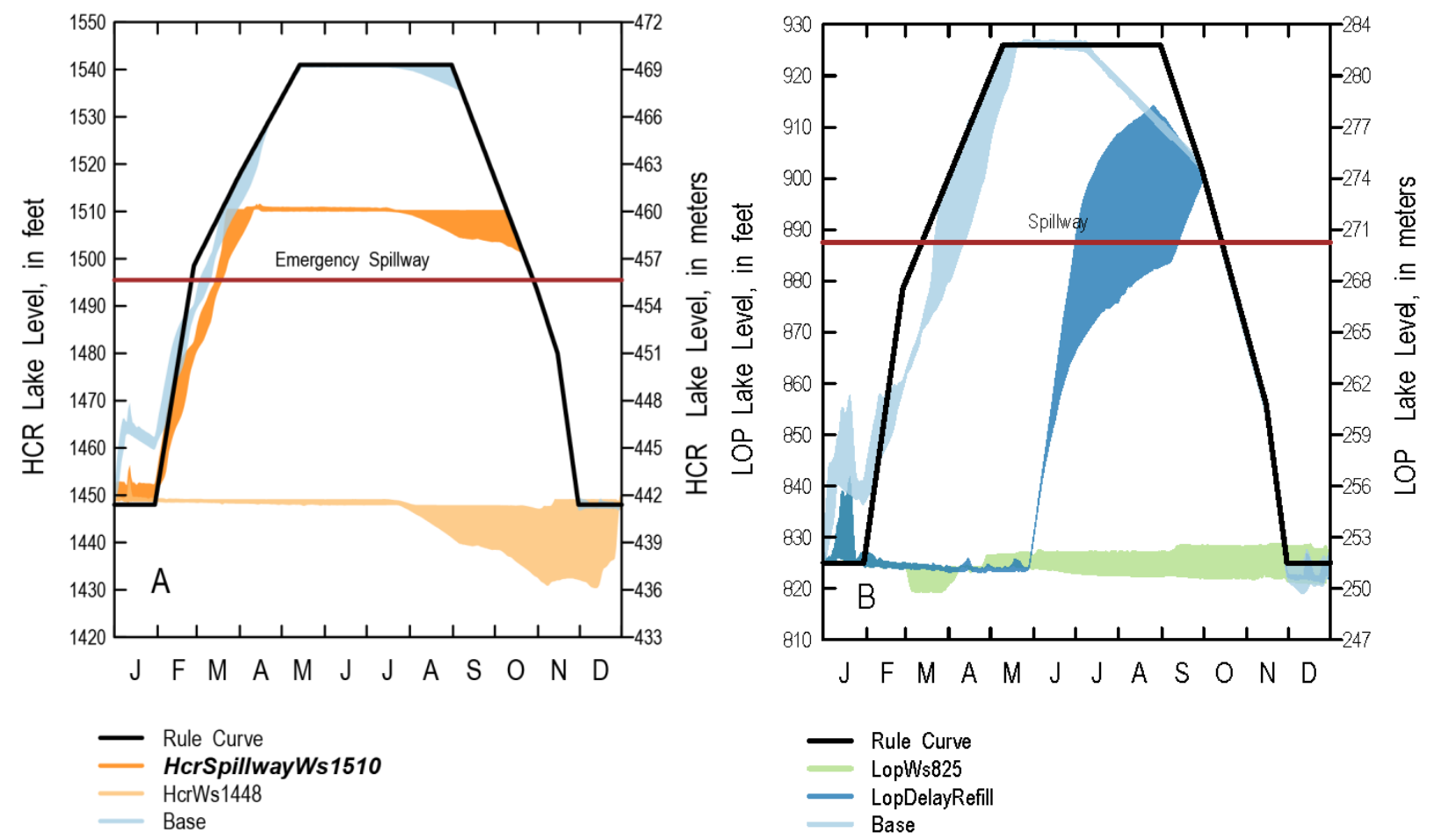

Figure 7. Graphs showing simulated range in lake levels at (A) Hills Creek Lake (HCR), and (B) Lookout Point Lake (LOP), Oregon, under multiple operational model scenarios averaged across wet, normal, and dry environmental scenarios, January-December. See table 2 for explanation of scenario names. The rule curve is the current target schedule of lake levels throughout the year.

The sources of streamflow to LOP varied substantially among the various HCR operational scenarios. These differences were quantified by computing a 15-day average streamflow for each operational/structural scenario over the wet, normal, and dry environmental scenarios at locations near the mouths of the three major tributaries to the MFWR upstream of LOP (Salt Creek, Salmon Creek, and NFMFWR). The relative flow contributions from these tributaries ranged from 7 to 42 percent of the total MFWR flow depending on the time of year and the operational scenario (fig. 8), clearly indicating the importance of these three tributaries to the flow and temperature of the MFWR. Of the three tributaries, NFMFWR typically had the greatest flow percentage. Lower contribution percentages from tributaries occurred during the drawdown period of Base operations during September-November. Operational scenario HcrWs1448, which held the HCR lake level relatively low year-round, resulted in similar average flow contributions compared to calculated flows without Hills Creek Dam in place (scenario woHCDam). 

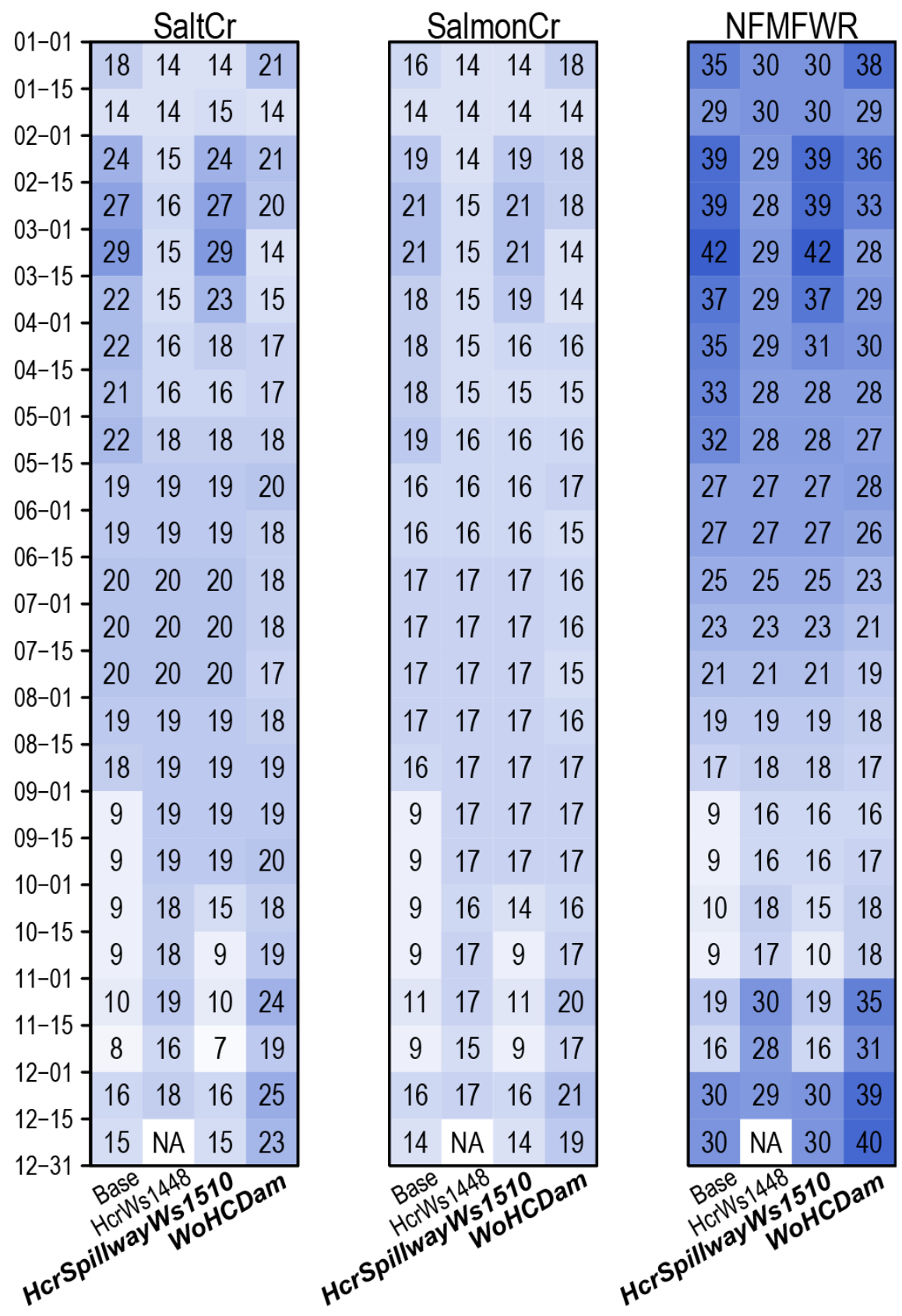

Figure 8. Diagrams showing calculated 15-day average streamflow contributions (percentage) from tributaries to the Middle Fork Willamette River in the reach between Hills Creek Dam and Lookout Point Lake, Oregon. Dates are shown in MM-DD format, and relatively larger percentages are highlighted with darker shading. SaltCr, Salt Creek; SalmonCr, Salmon Creek; NFMFWR, North Fork of Middle Fork Willamette River; NA, no data. See table 2 for explanation of scenario names; woHCDam is a scenario analysis done without the Hills Creek Dam in place. 


\section{Structural Scenarios}

The Base structural scenarios represent the existing operations and usable outlet structures at Hills Creek (power penstocks and ROs) and Lookout Point (spillways, power penstocks, and ROs) Dams, often with a priority on power generation that limits "spill” (releases through the spillway or RO at Lookout Point Dam and through the RO at Hills Creek Dam) to a maximum of 60 percent of the total outflow. Typically, the need to meet the operational temperature target resulted in spillway releases during summer (accessing warmer surface water to meet a warm temperature target) and RO releases during autumn (accessing cooler, deeper water to meet a cool temperature target) at Lookout Point Dam as well as some summer RO releases at Hills Creek Dam. The remaining 40 percent (0.4) of flow was released through the powerhouse outlet (see "Base:Power” under MINFRAC values in table 3).

No attempt was made to meet the temperature target for the NoBlend scenario, and all outflow was routed to the powerhouse outlet (table 4). Aside from occasional spill releases during high-flow events, this scenario was similar to operations at Lookout Point Dam prior to 2012 and current operations at Hills Creek Dam. As temperature management has been incorporated in operations at Lookout Point Dam since 2012, some releases have been routed through the spillway during the summers of 2014 and 2015. This type of operation is represented in Base_LopSpillOnly (table 4). Hypothetical outlets floating $1 \mathrm{~m}$ below the lake surface, potential removal of any constraints on minimum power releases, and the introduction of new or altered outlets were included. Of particular note are scenarios that included a low fixed-elevation outlet $(1,300 \mathrm{ft}$ [396.2 m]) at Hills Creek Dam to release cool water during autumn to compensate for the lack of such a deep outlet among the existing outlet structures (scenario HcrFloat_Pow1300_noHcrppmin in table 4). The complete list of combinations and variations specified for each scenario is shown in table 4.

\section{Water Temperatures}

Model simulation results of the operational and structural scenarios were compared in several different ways, including side-by-side tables of the mean and range of simulated water temperatures under the three environmental scenarios at three primary locations: (1) immediately downstream of Hills Creek Dam (USGS streamgage 14145500, RM 232.5), (2) just upstream of LOP (about 1 mi upstream of the Hampton Landing boat ramp; USGS streamgage 14148000, RM 218.7), and (3) immediately downstream of Dexter Dam (RM 204). See appendix A for results from more locations in the MFWR reach between HCR and LOP. 
Table 4. Specification of power constraints, maximum lake elevations, refill and drawdown schedules, and outlet schemes for each operational and structural model scenario at Hills Creek and Lookout Point and Dams, Oregon.

[Shading denotes without-dams scenarios. NGVD 29, National Geodetic Vertical Datum of 1929; HCR, Hills Creek Lake; LOP, Lookout Point Lake; Feb, February; Sept, September; RO, regulating outlet]

\begin{tabular}{|c|c|c|c|c|c|c|c|c|}
\hline \multirow{3}{*}{ Scenario name } & \multicolumn{4}{|c|}{ Operations } & \multicolumn{4}{|c|}{ Structures } \\
\hline & \multicolumn{2}{|c|}{$\begin{array}{c}\text { Minimum power release } \\
\text { (percentage) }\end{array}$} & \multicolumn{2}{|c|}{$\begin{array}{l}\text { Maximum lake elevation } \\
\text { (feet above NGVD 29) }\end{array}$} & \multicolumn{2}{|c|}{ Refill/drawdown time } & \multicolumn{2}{|c|}{ Outlet scheme } \\
\hline & HCR & LOP & HCR & LOP & HCR & LOP & HCR & LOP \\
\hline \multicolumn{9}{|c|}{ Operational scenarios } \\
\hline NoBlend & 100 & 100 & 1,541 & 926 & Feb/Sept & Feb/Sept & Base & Base \\
\hline Base_LopSpillOnly & 40 & 40 & 1,541 & 926 & Feb/Sept & Feb/Sept & Base & Base; no RO \\
\hline Base & 40 & 40 & 1,541 & 926 & Feb/Sept & Feb/Sept & Base & Base \\
\hline NoHcrppmin & 0 & 40 & 1,541 & 926 & Feb/Sept & Feb/Sept & Base & Base \\
\hline Noppmin & 0 & 0 & 1,541 & 926 & Feb/Sept & Feb/Sept & Base & Base \\
\hline LopDelayRefill & 40 & 40 & 1,541 & 926 & Feb/Sept & May/Sept & Base & Base \\
\hline LopWs825 & 40 & 40 & 1,541 & 825 & Feb/Sept & No refill & Base & Base \\
\hline HcrWs1448 & 40 & 40 & 1,448 & 926 & No refill & Feb/Sept & Base & Base \\
\hline HcrWs1448_NoHcrppmin & 0 & 40 & 1,448 & 926 & No refill & Feb/Sept & Base & Base \\
\hline \multicolumn{9}{|c|}{ Structural scenarios } \\
\hline HcrSpillway & 40 & 40 & 1,541 & 926 & Feb/Sept & Feb/Sept & Spillway & Base \\
\hline HcrSpillwayWs1510 & 40 & 40 & 1,510 & 926 & Feb/Sept & Feb/Sept & Spillway & Base \\
\hline HcrFloat_NoHcrppmin & 0 & 40 & 1,541 & 926 & Feb/Sept & Feb/Sept & Floating outlet & Base \\
\hline HcrFloat_Noppmin & 0 & 40 & 1,541 & 926 & Feb/Sept & Feb/Sept & Floating outlet & Base \\
\hline HcrFloat_Pow1300_NoHcrppmin & 0 & 40 & 1,541 & 926 & Feb/Sept & Feb/Sept & $\begin{array}{l}\text { Floating, lower } \\
\text { outlet }\end{array}$ & Base \\
\hline LopFloat_NoLOPppmin & 40 & 0 & 1,541 & 926 & Feb/Sept & Feb/Sept & Base & Floating outlet \\
\hline $\begin{array}{l}\text { HcrFloat_Pow1300_LopFloat_ } \\
\text { Noppmin }\end{array}$ & 0 & 0 & 1,541 & 926 & Feb/Sept & Feb/Sept & $\begin{array}{l}\text { Floating, lower } \\
\text { outlet }\end{array}$ & Floating outlet \\
\hline Base_woHcr & & 40 & & 926 & & Feb/Sept & No dam & Base \\
\hline WoHcr_LopFloat_NoLOPppmin & & & & 926 & & Feb/Sept & No dam & Floating outlet \\
\hline WoDams & & & & & & & No dam & No dam \\
\hline
\end{tabular}




\section{Hill Creek Dam Scenario Effects on Middle Fork Willamette River Upstream of Lookout Point Dam}

Simulated release water temperatures from scenarios focused on operational or structural changes to HCR show that the tested scenarios had a wide range of results, and none matched the target release temperature completely (fig. 9). The results shown in figure 9 were averaged across the wet, normal, and dry scenarios, but they represent the central tendency of each operational and structural change and allow a comparison of results from June to December, when results varied the most among scenarios. These results, along with computations of the 15-day average and range of simulated temperatures for each HCR operational and structural scenario (figs. 10-11), provide several good ways to compare scenario results.

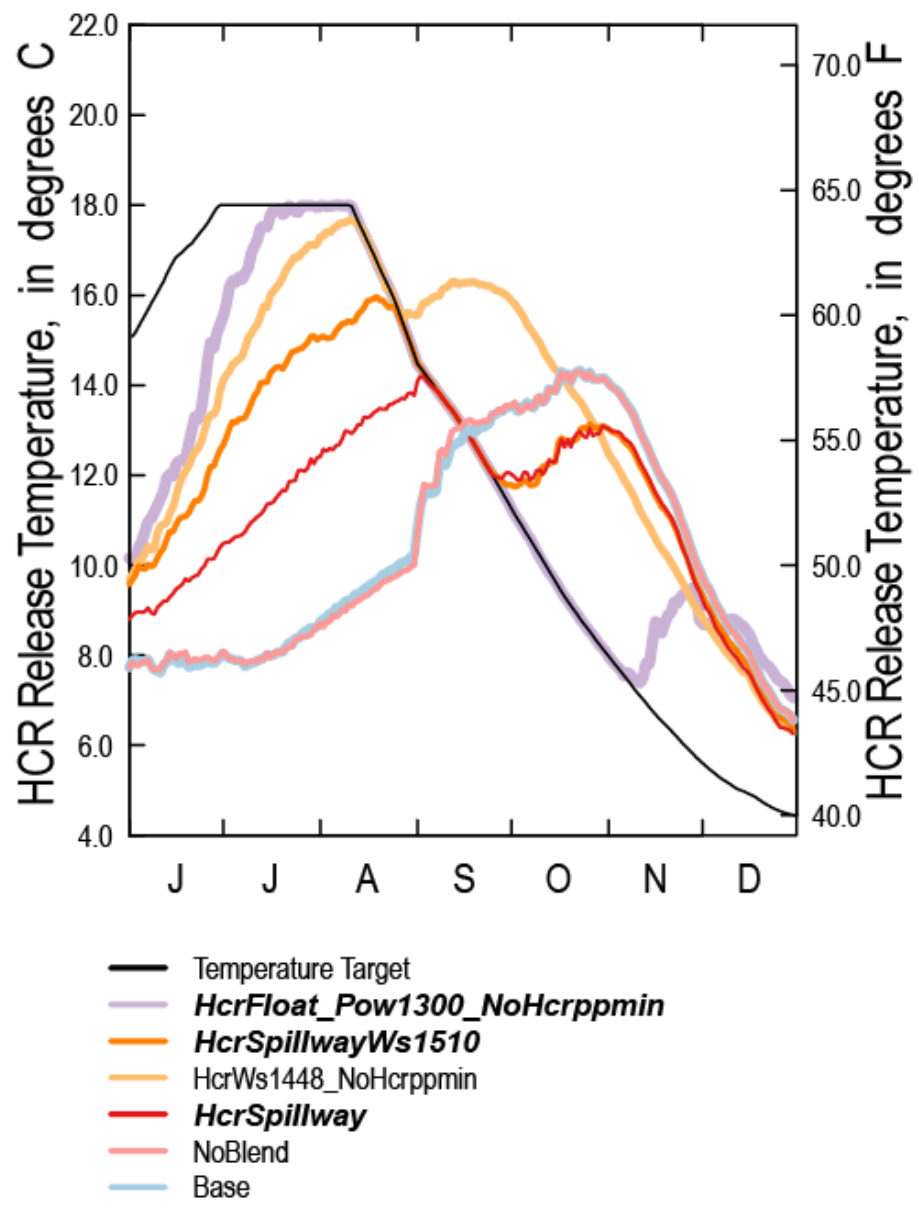

Figure 9. Graph showing simulated release water temperatures under various operational and structural scenarios downstream of Hills Creek Lake, Oregon, averaged across wet, normal, and dry scenarios, June-December. See table 4 for an explanation of the named scenarios. Black text indicates operational scenarios and bold italic text indicates structural scenarios. HcrWs1448_NoHcrppmin 


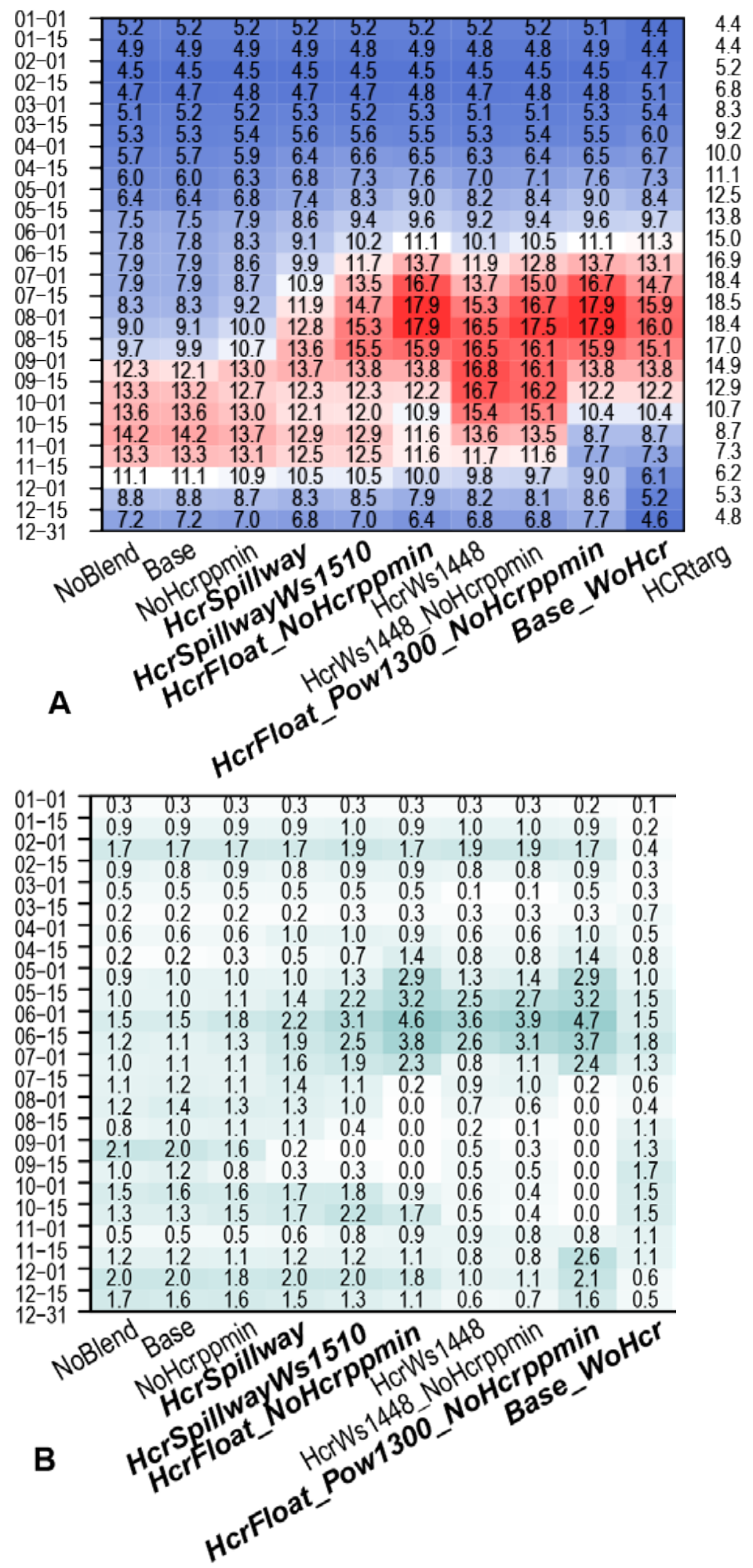

Figure 10. Diagrams showing simulated average (A) and range (B) of release water temperatures across wet, normal, and dry scenarios in 15-day intervals under operational and structural scenarios at Hills Creek Dam, Oregon. Scenarios are ordered by estimated emergence day at the head of Lookout Point Lake, from left to right. Dates are shown in MM-DD format. Black text indicates operational scenarios and bold italic text indicates indicate structural scenarios. See table 4 for an explanation of the named scenarios. HCRtarg, two-dimensional hydrodynamic and water-quality model (CE-QUAL-W2) temperature target at Hills Creek Dam. 


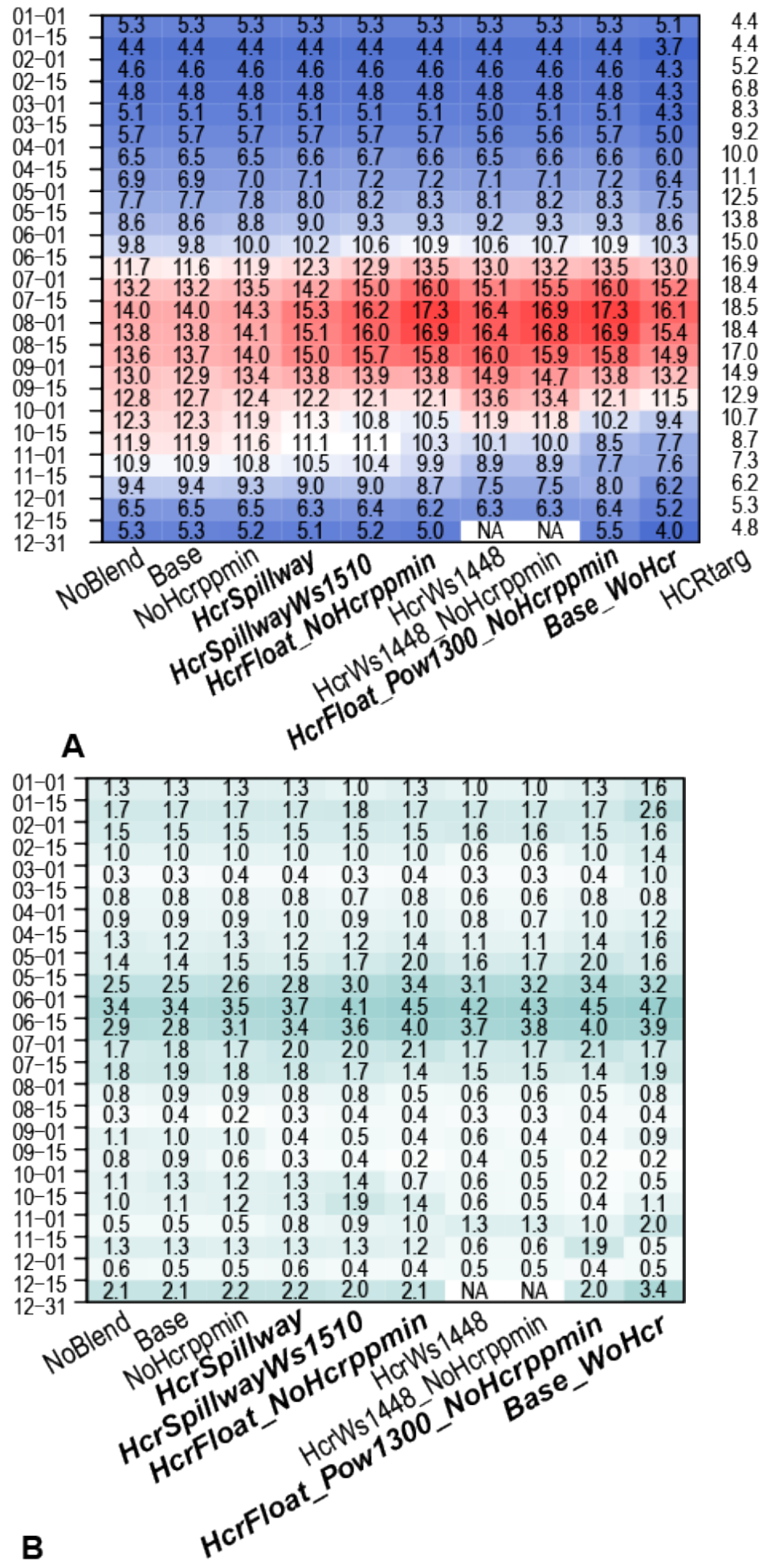

Figure 11. Diagrams showing simulated average (A) and range (B) of water temperature at the head of Lookout Point Lake across wet, normal, and dry scenarios in 15-day intervals under operational and structural scenarios at Hills Creek Dam, Oregon. Scenarios are ordered by estimated emergence day at the head of LOP, from left to right. Dates are shown in MM-DD format. Black text indicates operational scenarios and bold italic text indicates structural scenarios. Values below and above 11.0 degrees Celsius in (A) are shaded blue and red, respectively. Higher range values in (B) are shaded darker blue. See table 4 for an explanation of the named scenarios. HCRtarg, two-dimensional hydrodynamic and water-quality model (CE-QUAL-W2) temperature target at Hills Creek Dam; NA, no data]. 
"Percent spill" is defined as the percentage of the total flow release directed to outlets other than the power penstocks; thus, spill includes the total releases from the RO and any other additional hypothetical structure at Hills Creek Dam (fig. 12; table 5). Although the RO is used at certain times of the year under Base operational scenarios and the percent spill is nonzero, temperature management at Hills Creek Dam is not particularly viable with existing outlet structures and the operational temperature target is rarely achieved for more than a few days. This inability to meet the temperature target is primarily due to the relatively deep location of the RO and power outlets and the lack of a routinely operable spillway at the dam. Release temperatures from HCR under Base and NoBlend scenarios were nearly identical $\left(<0.2^{\circ} \mathrm{C}\right.$ as a 15 -day difference) near Hills Creek Dam and downstream at the head of LOP because releases from the RO were from nearly the same depth as the power outlets at Hills Creek Dam. Additionally, no usable outlets are present near the surface or near the bottom of HCR, which allows little opportunity to release warm surface water in summer or cool deep water during autumn.

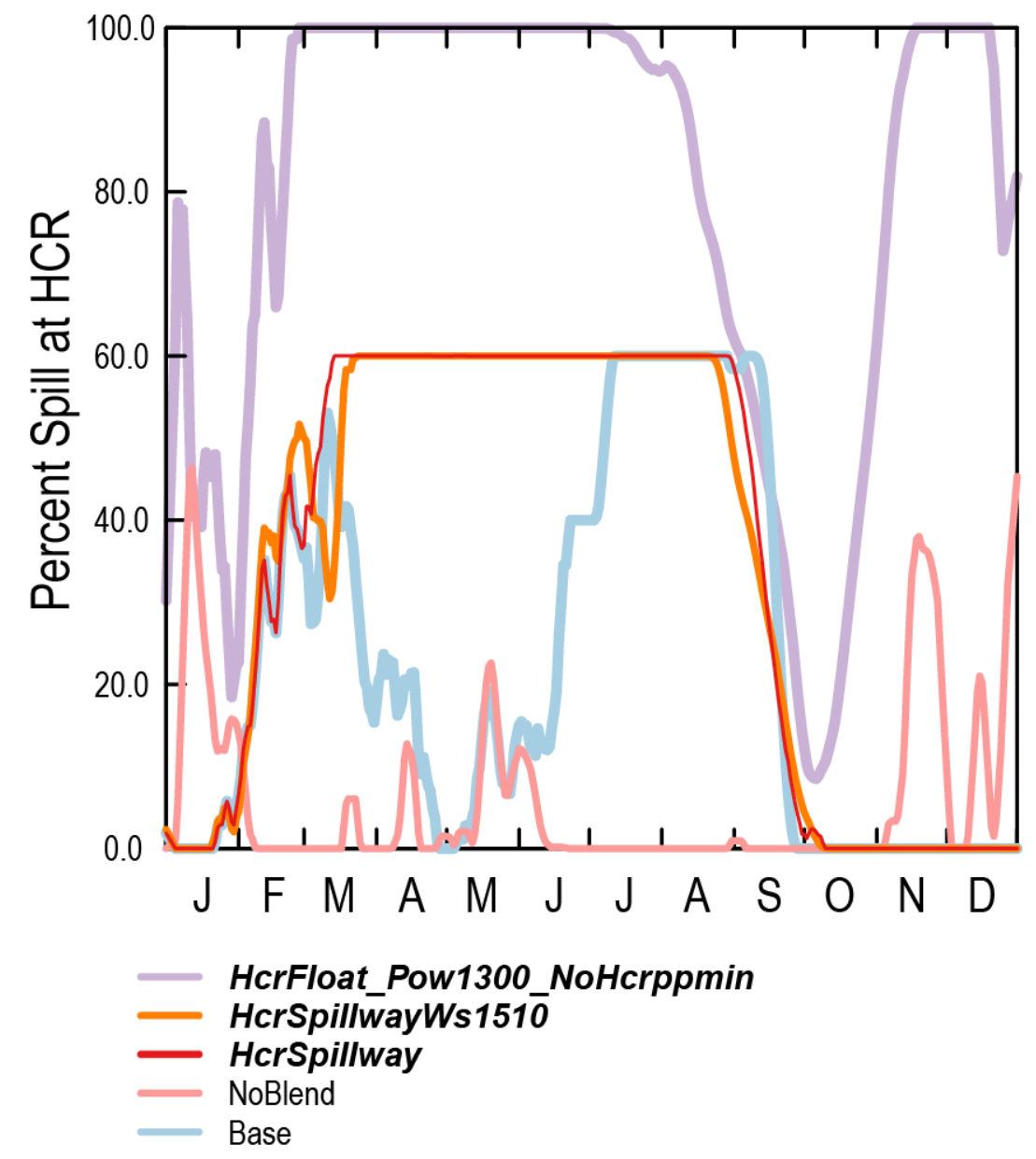

Figure 12. Graph showing simulated percent spill from Hills Creek Dam, Oregon under various operational and structural scenarios, averaged across wet, normal, and dry scenarios, January-December. Black text indicates operational scenarios and bold italic text indicates structural scenarios. See table 4 for an explanation of the named scenarios. 
Table 5. Percent spill for releases under operational and structural scenarios, where the minimum, mean, and maximum percentages are from annual averages for each of the environmental scenarios (wet, normal, and dry), Hills Creek Dam, Oregon.

["Percent spill" is defined as the percentage of total flow release directed to outlets other than the power penstocks. Scenario name: Black text indicates operational scenarios; bold italic text indicates structural scenarios. See table 4 for an explanation of the named scenarios]

\begin{tabular}{lccc}
\hline \multicolumn{1}{c}{ Scenario name } & $\begin{array}{c}\text { Minimum } \\
\text { spill } \\
\text { (percent) }\end{array}$ & $\begin{array}{c}\text { Mean } \\
\text { spill } \\
\text { (percent) }\end{array}$ & $\begin{array}{c}\text { Maximum } \\
\text { (spill) } \\
\text { (percent) }\end{array}$ \\
\hline NoBlend & 1 & 6 & 12 \\
Base & 14 & 22 & 31 \\
HcrWs1448 & 29 & 32 & 34 \\
HcrSpillwayWs1510 & 30 & 34 & 38 \\
HcrSpillway & 32 & 35 & 38 \\
HcrWs1448_NoHcrppmin & 50 & 53 & 56 \\
HcrFloat_NoHcrppmin & 54 & 58 & 61 \\
NoHcrppmin & 57 & 61 & 65 \\
HcrFloat_Pow1300_NoHcrppmin & 71 & 79 & 86 \\
\hline
\end{tabular}

The surface elevation of HCR was lowered under Ws1448_NoHcrppmin scenarios, resulting in smaller, warmer releases during the summer (compared to Base scenarios) until about mid-October when drawdown during Base operations brought stored summer heat from near the lake surface down to the level of the outlets (fig. 9). Although this caused lower release temperatures during NovemberDecember compared with Base scenarios, the scenario still did not achieve successful temperature control on an annual basis because of the relatively deep location and close proximity of the RO and power outlets. A relatively minor difference was observed between release temperatures from Ws1448 and Ws1448_NoHcrPpmin scenarios (fig. 10), especially outside July and August, again emphasizing the fact that using the RO or the power outlet at HCR makes little difference.

As hypothetical shallower or deeper outlets were added to the HCR model, more temperature control was achieved year-round. The addition of the emergency spillway as a usable outlet (HcrSpillway) achieved greater temperature control than Base conditions. The HcrSpillwayWs1510 scenario included a lower lake surface closer to the crest of the emergency spillway, putting that outlet closer to the warm water at the lake surface in summer. This resulted in warmer releases June through mid-September, followed by release temperatures nearly identical to those of HcrSpillway for midSeptember to December (figs. 9, 10A, 11A). The addition of a hypothetical floating outlet and a deeper fixed-elevation outlet below the existing power outlet in scenario HcrFloat_Pow1300_NoHcrppmin achieved the greatest amount of temperature control from HCR year-round and resulted in release temperatures that matched the operational target from mid-July to early November (fig. 9). 
Across all HCR scenarios, more temperature variability among the wet, normal, and dry environmental scenarios was evident during May-July, when no minimum flow rules for power outlets were in place and the operational temperature target was higher than the release temperature (fig. 10B). Although the model was attempting to release warm water during May-July, variability of the onset and depth of stratification, caused by the timing of warm weather systems in different calendar years, affected the potential release temperatures. Moving downstream of HCR to the Hampton Landing boat ramp at the head of LOP, the variability among environmental scenarios increased as unregulated streams entered the system and the MFWR became more equilibrated with the ambient air temperature, especially during May-July (fig. 11B).

As releases from Hills Creek Dam moved downstream and mixed with inputs from NFMFWR, Salt Creek, and Salmon Creek tributaries, a substantial amount of heat was exchanged across the streambed-water and air-water interfaces, depending on the time of year. As much as an average increase or decrease of $+5.7 /-2.3^{\circ} \mathrm{C}$ was gained or lost during summer and autumn between Hills Creek Dam and the Hampton Landing Boat Ramp (comparing Base scenario in figs. 10A and 11A). Although most HCR scenarios warmed in this reach during July and August because of unseasonably cool releases for that time, some scenarios (HcrWs1488, HcrFloat_noHcrppmin, HcrFloat_Pow1300_noHcrppmin) cooled by as much as $1.1^{\circ} \mathrm{C}$ because of relatively warm releases compared to without-dams temperatures (Base_woHcr) (figs. 10A, 11A). The heat gain and loss in this reach also was proportional to the amount of flow from Hills Creek Dam under each operational scenario. Lower autumn release rates in HcrWs1448, resulted in faster cooling from HCR to LOP compared to Base scenarios. This effect was most pronounced during October, when HcrWs1448 cooled by about $3{ }^{\circ} \mathrm{C}$ from HCR to LOP and Base operations cooled by about $2{ }^{\circ} \mathrm{C}$ (comparing figs. 10A and 11A). The hypothetical structural scenario of HcrFloat_Pow1300_noHcrppmin at HCR was closest to the without-dams scenario (Base_woHcr), averaging no more than $1.8^{\circ} \mathrm{C}$ greater than Base_woHcr at the head of LOP (fig. 11A).

\section{Lookout Point-Dexter Lakes}

Operational and structural scenarios for Hills Creek and Lookout Point Dams were assessed downstream of Dexter Dam to show the combined effect from all three MFWR projects (HCR, LOP, DEX). Simulated water temperatures downstream of DEX from scenarios focused on operational or structural changes to HCR and LOP showed varied levels of success in controlling temperature releases (fig. 13). These results were averaged across wet, normal, and dry scenarios, but they represent the central tendency of each operational and structural change and allow a comparison of results from June to December, when results vary the most among scenarios. Downstream of DEX, scenarios focused on changes at HCR generally led to a smaller magnitude of change compared to scenarios focused on changes at LOP (comparing figs. 13A and 13B). For example, the most extreme structural scenario at HCR (HcrFloat_Pow1300_noHcrppmin) resulted in less than $1.0^{\circ} \mathrm{C}$ difference when compared to Base scenarios downstream of DEX. This result shows the extent to which releases from Hills Creek Dam (under an extreme temperature-management scenario) lose their upstream characteristics and become more equilibrated with tributary inflows, solar radiation, and conditions in LOP as that water moves downstream to Lookout Point and Dexter Dams. 

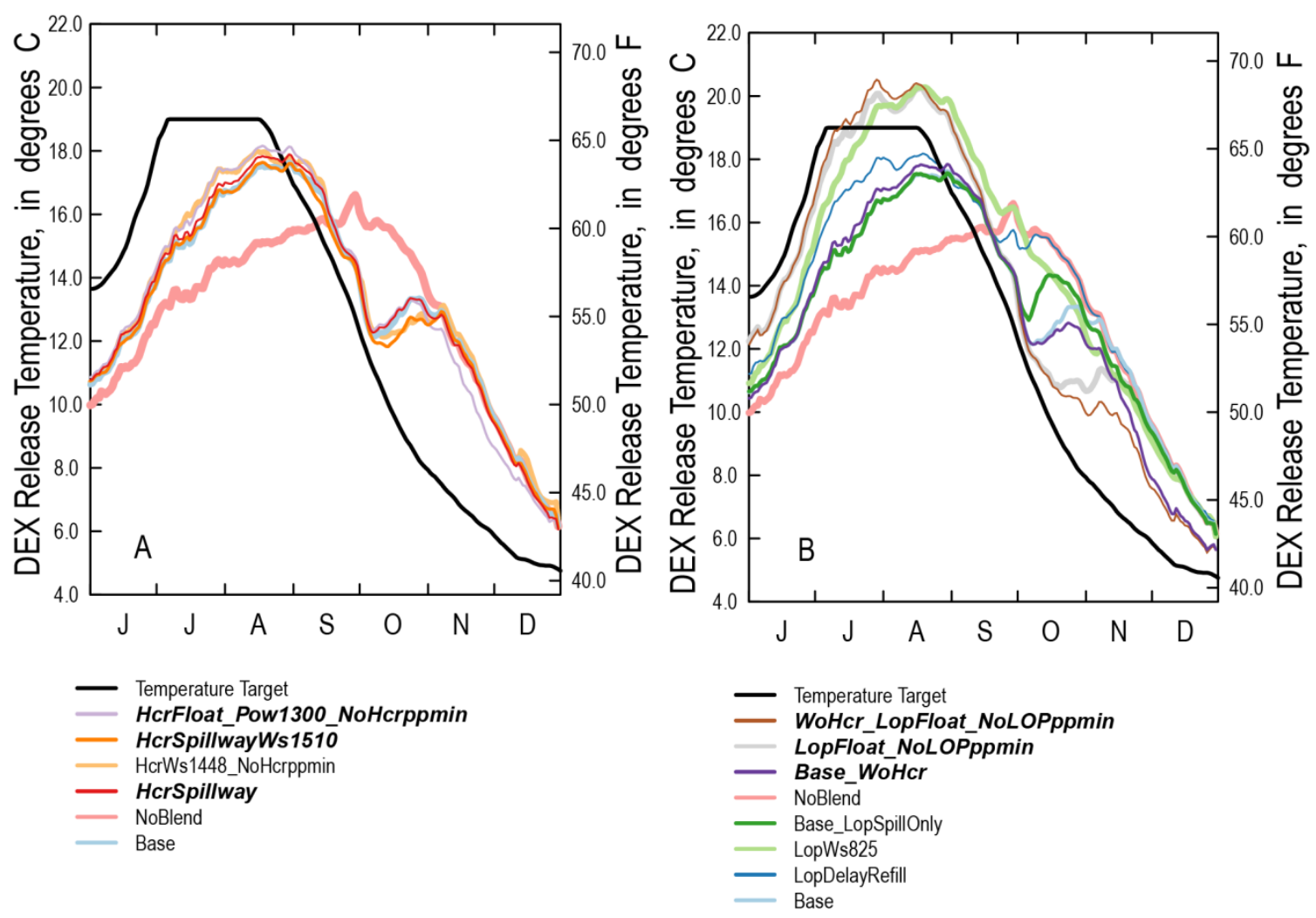

Figure 13. Graphs showing simulated release water temperatures immediately downstream of Dexter Dam, Oregon, under operational and structural scenarios averaged across wet, normal, and dry scenarios at $(A)$ Hills Creek Dam and (B) Lookout Point Dam, June-December. Black text indicates operational scenarios and bold italic text indicates structural scenarios. See table 4 for an explanation of the named scenarios.

Operational scenarios at LOP consisted of current operations with and without minimum flows through power outlets (Base, Noppmin), delaying the date when refill of the lake began (LopDelayRefill), holding the lake surface at minimum conservation level (825 ft) year-round (LopWs825), and limiting blending to the power and RO outlets only (Base_LopSpillOnly). Although these operational scenarios resulted in less percent spill (fig. 14, table 6) (greater potential power production), they also resulted in warmer releases year-round compared to Base operations. LopDelayRefill and LopWs825scenarios consisted of release rates below the current minimum flow rules at DEX during June-August (fig. 6B). 


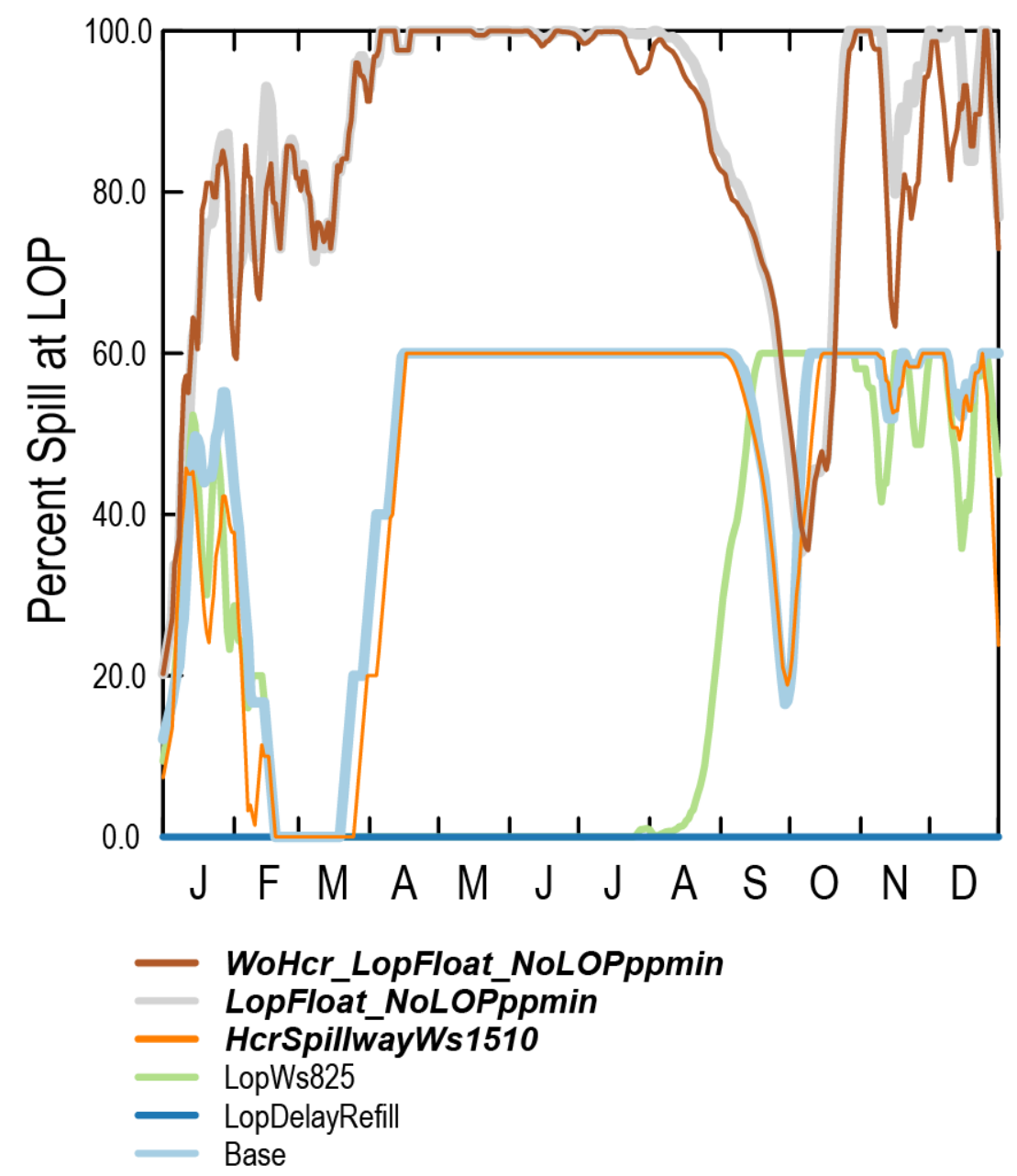

Figure 14. Graph showing simulated percent spill from Lookout Point Dam, Oregon, under various operational and structural scenarios averaged across wet, normal, and dry scenarios, January-December. Black text indicates operational scenarios and bold italic text indicates structural scenarios. See table 4 for an explanation of the named scenarios. 
Table 6. Percent spill for releases from Lookout Point Lake, Oregon. under operational and structural scenarios, where the minimum, mean, and maximum percentages are from annual averages for each of the environmental scenarios (wet, normal, and dry).

["Percent spill" is defined as the percentage of the total flow release directed to outlets other than the power penstocks. Scenario name: Black text indicates operational scenarios; bold italic text indicates structural scenarios. See table 4 for an explanation of the named scenarios]

\begin{tabular}{lccc}
\hline \multicolumn{1}{c}{ Scenario name } & $\begin{array}{c}\text { Minimum } \\
\text { spill } \\
\text { (percent) }\end{array}$ & $\begin{array}{c}\text { Mean } \\
\text { spill } \\
\text { (percent) }\end{array}$ & $\begin{array}{c}\text { Maximum } \\
\text { spill } \\
\text { (percent) }\end{array}$ \\
\hline NoBlend & 0 & 0 & 0 \\
LopDelayRefill & 0 & 0 & 0 \\
LopWs825 & 17 & 22 & 28 \\
Base_LopSpillOnly & 26 & 29 & 31 \\
HcrSpillwayWs1510 & 39 & 45 & 51 \\
HcrFloat_Pow1300_NoHcrppmin & 40 & 47 & 53 \\
Base_WoHcr & 40 & 47 & 53 \\
HcrSpillway & 41 & 47 & 53 \\
HcrFloat_NoHcrppmin & 41 & 47 & 53 \\
Base & 41 & 47 & 53 \\
NoHcrppmin & 41 & 47 & 53 \\
HcrWs1448 & 44 & 49 & 53 \\
HcrWs1448_NoHcrppmin & 44 & 49 & 53 \\
HcrFloat_Noppmin & 64 & 76 & 88 \\
Noppmin & 65 & 77 & 88 \\
HcrFloat_Pow1300_LopFloat_Noppmin & 72 & 85 & 95 \\
WoHcr_LopFloat_NoLOPpmin & 71 & 85 & 95 \\
LopFloat_NoLOPppmin & 74 & 87 & 96 \\
\hline
\end{tabular}

The 15-day temperature mean and range of each operational and structural scenario at the location immediately downstream of DEX for the entire calendar year shows a distinct seasonal pattern in temperature, but with some variation among scenarios (figs. 15-16). The addition of a hypothetical floating outlet at Lookout Point Dam and removal of power generation constraints (scenario LopFloat_NoLOPppmin) resulted in release temperatures much closer to the operational temperature target for most of the year until late-October. Similarly, two variants of this scenarioHcrFloat_Pow1300_LopFloat_noppmin (floating and lower fixed outlets at Hills Creek Dam) and WoHcr_LopFloat_NoLOPppmin (no Hills Creek Dam)—resulted in similar release temperatures and percent spill (figs. 13B, 14, 15). Although these scenarios achieved some agreement with the operational temperature targets, they also released water mid-July to early October that exceeded the maximum threshold of $19^{\circ} \mathrm{C}$, which could be a problem if such scenarios actually were carried out (fig. 15). Downstream of DEX, relatively little temperature difference (less than $0.4^{\circ} \mathrm{C}$ August-December) was observed between hypothetical floating outlet scenarios at HCR (HcrFloat_noppmin) or LOP (LopFloat_NoLOPppmin) (fig. 15). 


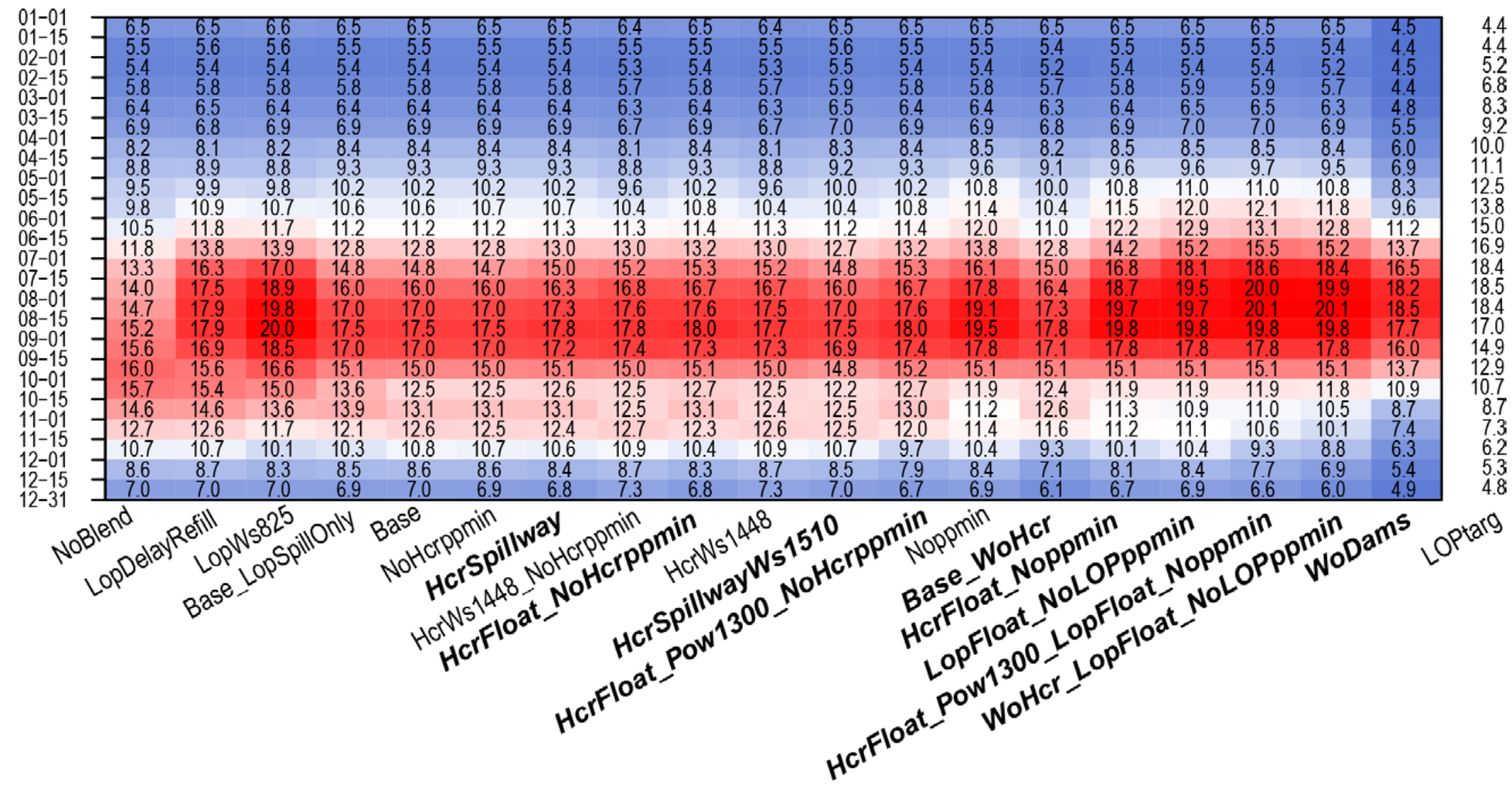

Figure 15. Graph showing simulated average release water temperature downstream of Dexter Dam, Oregon, in 15-day intervals over wet, normal, and dry scenarios from various operational and structural scenarios at Hills Creek and Lookout Point Dams. Scenarios are ordered by estimated emergence day downstream of Dexter Dam, from left to right. Dates are shown in MM-DD format. Black text indicates operational scenarios and bold italic text indicates structural scenarios. Values below and above 11.0 degrees Celsius are shaded blue and red, respectively. See table 4 for an explanation of the named scenarios. LOPtarg, two-dimensional hydrodynamic and water-quality model (CE-QUAL-W2) temperature target at Lookout Point Dam. 


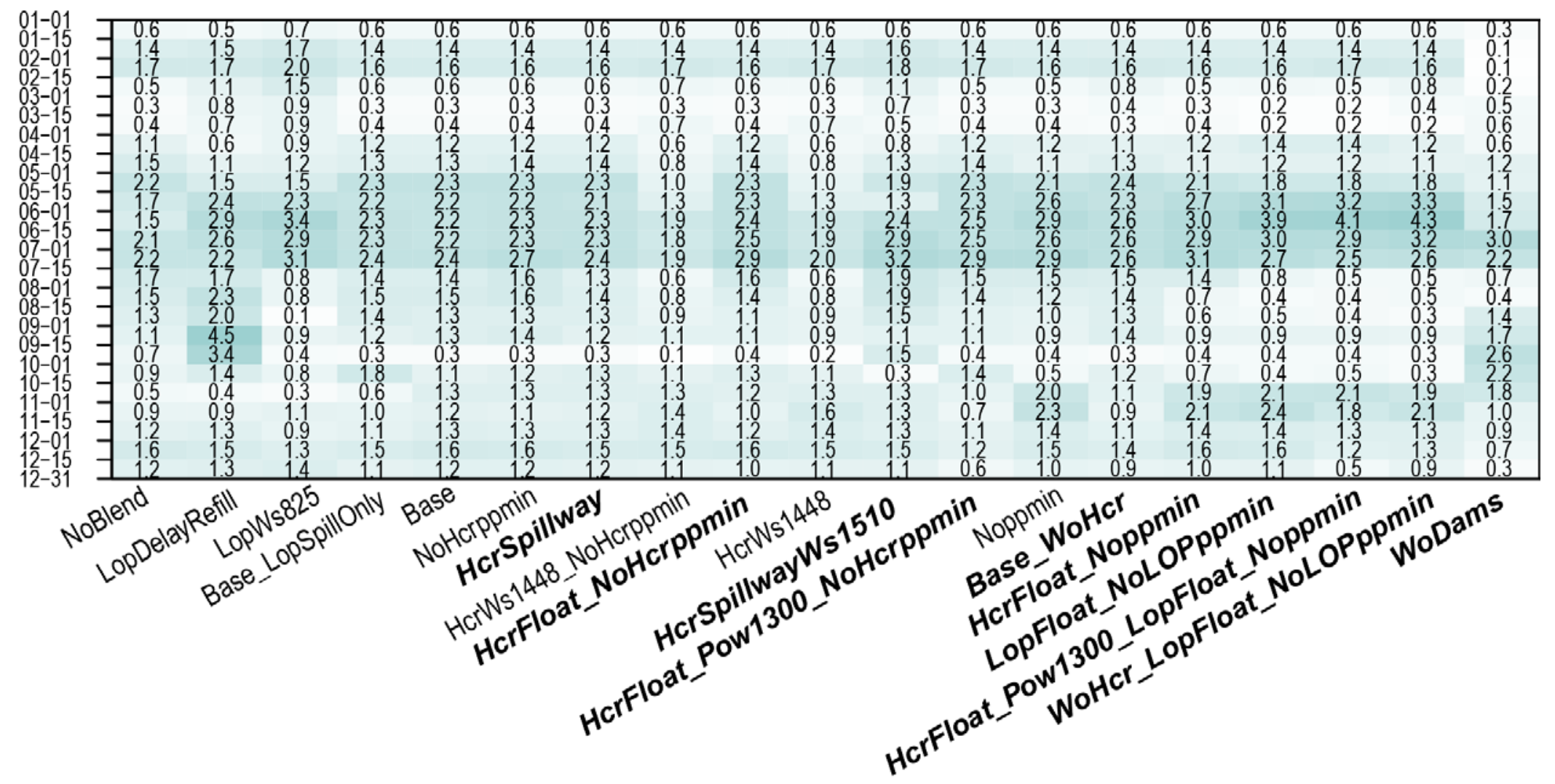

Figure 16. Graph showing simulated average release water temperature daily range at Dexter Dam, Oregon, in 15-day intervals over wet, normal, and dry scenarios from various operational and structural scenarios at Hills Creek and Lookout Point Dams. Scenarios are ordered by estimated emergence day downstream of Dexter Dam, from left to right. Dates are shown in MM-DD format. Black text indicates operational scenarios and bold italic text indicates structural scenarios. Higher range values in (B) are shaded darker blue. See table 4 for an explanation of the named scenarios. 


\section{Estimated Emergence Days}

The U.S. Army Corps of Engineers (2012) has proposed the “accumulated thermal unit” (ATU) as a useful metric to estimate the date when salmon fry might emerge from eggs. The ATU is the cumulative sum of daily mean water temperatures greater than $32^{\circ} \mathrm{F}$, beginning on September 20 of each year. The estimated emergence day then was determined as the date when the ATU value reached $1,750{ }^{\circ} \mathrm{F}$-days. When scenarios did not meet the $1,750^{\circ} \mathrm{F}$-day threshold before December 31 , scenario results from January 1 were concatenated to the end of the calendar year. The estimated emergence day calculation allows scenarios to be compared using a single metric at key locations along the MFWR study area during the critical autumn period in which current dam operations (NoBlend, Base scenarios) have resulted in early egg emergence relative to pre-dam conditions (Keefer and Caudill, 2010).

Wet, normal, and dry scenario-averaged emergence days showed a substantial range, from late November or early December at most locations, to January or later under some scenarios (table 7). Estimated emergence days were 25 to 46 days later at the head of LOP compared to the location 13.8

RM upstream at Hills Creek Dam under scenarios at HCR. Operational scenarios with the greatest delay in estimated emergence between HCR and LOP specified lower lake elevations and lower summer outflows (23 days delay comparing HcrWs1448 to Base and NoBlend scenarios in table 7). Current temperature-management operations at HCR (Base) resulted in average estimated emergence 60 days earlier than WoDams scenarios at the head of LOP. Immediately downstream of DEX, Base operations at both HCR and LOP resulted in average estimated emergence 10 days later than NoBlend scenarios and 78 days earlier than WoDams scenarios. Structural scenarios at HCR (not including without-dams scenarios) resulted in 9-34 days delayed emergence at the head of LOP, but no more than 3 days delay downstream of DEX compared to Base operations. Structural scenarios including a floating outlet at HCR (HcrFloat_Noppmin) or LOP (LopFloat_NoLOPppmin) resulted in similar delays in estimated emergence (9 and 10 days, respectively) compared to Base operations downstream of DEX. Scenarios including hypothetical floating outlets at HCR and LOP (HcrFloat_Pow1300_LopFloat_Noppmin) led to an additional 4 days in delay of emergence, compared to Base operations downstream of DEX. 
Table 7. Estimated emergence day for a range of locations and model scenarios, based on Accumulated Thermal Unit calculations starting on day 263 of the year and ending at 1,750 degree Fahrenheit-days.

[Table entries are ordered from top to bottom by emergence day immediately downstream of Dexter Dam. Scenario name: Black text indicates operational scenarios; bold italic text indicates structural scenarios. Abbreviations: LOP, Lookout Point Lake; LOP-DEX, Lookout Point-Dexter Lakes; MFWR, Middle Fork Willamette River; USGS, U.S. Geological Survey. See table 4 for and explanation of the named scenarios.]

\begin{tabular}{|c|c|c|c|c|c|c|}
\hline Landmark: & Hills Creek Dam & $\begin{array}{c}\text { USGS } \\
\text { streamgage } \\
14145500 \\
\end{array}$ & Salt Creek & Salmon Creek & Head of LOP & Dexter Dam \\
\hline Model segment: & HCR Outflow & MFWR 11 & MFWR 14 & MFWR 27 & MFWR 85 & LOP-DEX Outflow \\
\hline River mile: & 232.5 & 231.4 & 231 & 229.4 & 218.7 & 204 \\
\hline \multicolumn{7}{|l|}{ Scenario name } \\
\hline NoBlend & $12-03$ & $12-04$ & $12-12$ & $12-18$ & $12-28$ & $11-28$ \\
\hline LopDelayRefill & $12-03$ & $12-04$ & $12-12$ & $12-18$ & $12-28$ & $11-29$ \\
\hline LopWs825 & $12-03$ & $12-04$ & $12-12$ & $12-18$ & $12-28$ & $12-03$ \\
\hline Base_LopSpillOnly & $12-03$ & $12-04$ & $12-12$ & $12-18$ & $12-28$ & $12-06$ \\
\hline Base & $12-03$ & $12-04$ & $12-12$ & $12-18$ & $12-28$ & $12-08$ \\
\hline NoHcrppmin & $12-07$ & $12-07$ & $12-16$ & $12-23$ & 01-02 & $12-08$ \\
\hline HcrSpillway & $12-13$ & $12-14$ & $12-24$ & 01-01 & 01-09 & $12-08$ \\
\hline HcrWs1448_NoHcrppmin & $12-05$ & $12-07$ & $12-31$ & 01-11 & $01-20$ & $12-09$ \\
\hline HcrFloat_NoHcrppmin & $12-23$ & $12-24$ & 01-07 & $01-12$ & $01-17$ & $12-09$ \\
\hline HcrWs1448 & $12-03$ & $12-05$ & $12-28$ & 01-08 & 01-19 & $12-09$ \\
\hline HcrSpillwayWs1510 & $12-13$ & $12-13$ & $12-26$ & 01-02 & 01-09 & $12-10$ \\
\hline HcrFloat_Pow1300_NoHcrppmin & $01-12$ & 01-12 & $01-28$ & 01-30 & 02-01 & $12-11$ \\
\hline Noppmin & $12-07$ & $12-07$ & $12-16$ & $12-23$ & 01-02 & $12-16$ \\
\hline Base_WoHcr & $03-25$ & $03-24$ & 04-01 & $03-14$ & $02-26$ & $12-16$ \\
\hline HcrFloat_Noppmin & $12-23$ & $12-24$ & 01-07 & $01-12$ & $01-17$ & $12-17$ \\
\hline LopFloat_NoLOPppmin & $12-03$ & $12-04$ & $12-12$ & $12-18$ & $12-28$ & $12-18$ \\
\hline HcrFloat_Pow1300_LopFloat_Noppmin & $01-12$ & $01-12$ & $01-28$ & 01-30 & $02-01$ & $12-22$ \\
\hline WoHcr_LopFloat_NoLOPppmin & $03-25$ & $03-24$ & 04-01 & 03-14 & $02 / 26$ & $12-29$ \\
\hline WoDams & $03-25$ & $03-24$ & 04-01 & 03-14 & $02-26$ & $02-24$ \\
\hline
\end{tabular}




\section{Summary}

In this study, 19 hypothetical operational and structural scenarios at Hills Creek and Lookout Point Dams in the MFWR Basin in western Oregon were simulated using two-dimensional hydrodynamic and water-quality (CE-QUAL-W2) hydrodynamic and water-temperature models and evaluated at several locations under wet, normal, and dry hydrologic and meteorological conditions imposed throughout a calendar year. Scenarios were run with a goal of minimizing the thermal effects of Hills Creek and Lookout Point Dams, focusing on warm lake-surface releases during May-August, and cool, deep releases during September-December. Operational scenarios included options such as modified release rates, variations in the timing of refill and drawdown, relaxation of minimum power generation requirements, and maintaining different maximum lake levels at HCR and LOP. Structural scenarios included various combinations of hypothetical floating outlets near the lake surface at HCR and LOP, use of the emergency spillway at Hills Creek Dam, and use of a hypothetical deep, fixedelevation outlet (at an elevation of 1,300 ft [396.2 m]) near the base of Hills Creek Dam. Three of the 19 scenarios were used to compare and evaluate potential alternatives: (1) post-2012 operational rules (Base), (2) pre-2012 operational rules (NoBlend), and (3) estimated temperatures without the dams in place (WoDams).

Temperatures simulated with many of the structural scenarios resembled without-dam conditions for part of the year, but most scenarios limited to operational changes had to specify reduced or no power generation at LOP to achieve a similar magnitude of change. The existing outlets at Lookout Point Dam (spillway, power, and regulating outlet [RO]) have depths and characteristics that allow relatively greater temperature control-less difference between release temperatures and the operational target - than existing structural options at Hills Creek Dam, which has only two relatively deep usable outlets (RO and power). Although temperature management through reduced power production at HCR had a minimal effect because of the limited depth range of the available outlets, reduced power production at LOP during summer (increased surface releases from the spillway) and autumn (increased deep, cool RO releases) led to greater temperature control at LOP.

The estimated emergence day of salmonid eggs was used as a metric to compare the relative efficacy of different scenarios for achieving improved temperatures in the MFWR. Accumulated Thermal Units, or the cumulative sum of daily mean water temperatures greater than $32{ }^{\circ} \mathrm{F}$, starting on September 20 (Julian day 263 of each simulation), were used to estimate that emergence day for each scenario. This egg incubation period is the time of the year most altered and critical for salmonids since the construction of the dams during the 1950s and 1960s. Scenarios limited to operational changes at HCR resulted in relatively little temperature control downstream of Hills Creek Dam, potentially extending the estimated emergence date by only 4 days near HCR and 23 days at the head of LOP, on average, compared to Base scenarios. Current temperature-management operations at HCR and LOP (Base) resulted in average estimated emergence 10 days later than NoBlend (no attempt at temperature control) scenarios and 78 days earlier than WoDams (without dams) scenarios immediately downstream of Dexter Lake (DEX).

The operational changes providing the greatest amount of temperature control resulted from absolving the LOP model of minimum flow requirements through the power penstocks and (or) keeping HCR at minimum conservation pool elevation (1,448 ft) year round. The latter scenario resulted in smaller, warmer releases from HCR June-October and cooler releases November-December compared to Base operations. The relative benefit of any particular scenario depended on the location in the MFWR system that was used to assess the potential change, bounded by current and without-dam conditions. Inputs from unregulated streams between HCR and LOP (Salt Creek, Salmon Creek, and 
North Fork of the Middle Fork Willamette River) helped achieve more natural stream temperatures in the MFWR before the MFWR entered LOP. Rapid temperature equilibration with the surrounding environment and dilution of HCR releases from these tributaries led to less variability among scenarios in the temperature 13.8 river miles downstream near the head of LOP relative to temperatures immediately downstream of HCR. Similar heat-exchange and dilution processes occur downstream of Dexter Dam, providing some mitigation of the upstream temperature alterations by the dams (see Rounds, 2010), but those effects were not assessed in this study.

Scenarios that were allowed to release as much surface or deep water as possible to meet the operational temperature target resulted in greater year-to-year variability during spring and to a lesser extent, during autumn. This was evident as the models were attempting to meet a temperature target that was greater than or less than the limitations of the potential release temperature of the lakes, delaying the transfer of some heat captured in summer to be released in autumn. For example, variability among the wet, normal, and dry years was greatest during May-July, typically when the onset and intensity of summer heat varied and determined the availability and potential release of warmer surface water from the dams. Some year-to-year variability among structural scenarios was evident during October 15November 15, when the timing of early autumn storms affected the timing and magnitude of releases that were warmer than the temperature target.

Downstream of DEX, scenarios that focused on changes at HCR generally led to smaller temperature changes than scenarios that made changes at LOP. For example, the most extreme structural scenario at HCR (including hypothetical floating and deeper outlets) resulted in a cooling effect during autumn as large as $5.5^{\circ} \mathrm{C}$ immediately downstream of HCR, $3.4^{\circ} \mathrm{C}$ at the head of LOP, but $0.6{ }^{\circ} \mathrm{C}$ downstream of DEX compared to Base conditions. Structural scenarios at HCR resulted in 9-34 days of delayed emergence upstream of LOP, but no more than 3 days delay downstream of DEX compared to Base operations. Downstream of DEX, relatively little temperature difference (less than $0.4{ }^{\circ} \mathrm{C}$ AugustDecember) was observed between hypothetical floating outlet scenarios implemented separately at HCR or LOP.

Although a range of hydrologic and meteorological conditions were used as forcing conditions for the models in this study, climatic changes likely will impose significant changes to weather patterns, snowpack, streamflow, and upstream water temperature during the expected lifespan of Lookout Point and Hills Creek Dams and any potential temperature-control structure that may be designed for those dams. Future studies focused on further development of these scenarios may benefit greatly from incorporating projected changes to climate, snowpack, and High Cascade streamflows in the modeling and analysis.

\section{Acknowledgments}

The authors thank Adam Stonewall of the USGS Oregon Water Science Center for his assistance in model simulations at Lookout Point-Dexter Lakes, and Yoonhee Kim for her assistance with the Middle Fork Willamette River model reach between Hills Creek Dam and Lookout Point Lake.

\section{Supplemental Materials}

The models developed and refined during this study, along with the model source code and all model inputs, are available for download at http://or.water.usgs.gov/proj/mfw_ssr_temp/. 


\section{References Cited}

Alderdice, D.F., and Velsen, F.P.J., 1978, Relation between temperature and incubation time for eggs of Chinook Salmon (Oncorhynchus tshawytscha): Journal of the Fisheries Research Board of Canada, 1978, v. 35, no. 1, p. 69-75, doi:10.1139/f78-010, accessed December 23, 2015, at http://dx.doi.org/10.1139/f78-010.

Battelle Memorial Institute, 2013, Final independent external peer review report-Willamette River floodplain restoration study, lower coast and middle forks subbasins, Oregon: Prepared for U.S. Army Corps of Engineers, 69 p. [Also available at http://www.usace.army.mil/Portals/2/docs/civilworks/Project\%20Planning/peer/willamette_final_IEP R.pdf.]

Buccola, N.L., Rounds, S.A., Sullivan, A.B., and Risley, J.C., 2012, Simulating potential structural and operational changes for Detroit Dam on the North Santiam River, Oregon, for downstream temperature management: U.S. Geological Survey Scientific Investigations Report 2012-5231, 68 p. [Also available at http://pubs.usgs.gov/sir/2012/5231/.]

Buccola, N.L., Stonewall, A.J., Sullivan, A.B., Kim, Yoonhee, and Rounds, S.A., 2013, Development of CE-QUAL-W2 models for the Middle Fork Willamette and South Santiam Rivers, Oregon: U.S. Geological Survey Open-File Report 2013-1196, 55 p. [Also available at http://dx.doi.org/10.3133/ofr20131186.]

Cole, T.M., and Wells, S.A., 2011, CE-QUAL-W2-A two-dimensional, laterally averaged, hydrodynamic and water-quality model, version 3.7: U.S. Army Corps of Engineers, Instruction Report EL-11-1 [variously paged], accessed February 22, 2016, at http://www.ce.pdx.edu/w2/.

Gregory, S., Ashkenas, L., and Nygaard, C., 2007, Summary report to assist development of ecosystem flow recommendations for the Middle Fork and Coast Fork of the Willamette River, Oregon: Corvallis, Oregon State University, Institute for Water and Watersheds , 237 p. (accessed February 22, 2016, at http://hdl.handle.net/1957/5965).

Groot, C., and Margolis, L., eds., 1991, Pacific salmon life histories: Vancouver, Canada, University of British Columbia Press, 564 p.

Keefer, M.L., and Caudill, C.C., 2010, A review of adult salmon and steelhead life history and behavior in the Willamette River Basin-Identification of knowledge gaps and research needs: Prepared for U.S. Army Corps of Engineers, Portland District, Technical Report 2010-8, 71 p. [Also available at: http://www.webpages.uidaho.edu/uiferl/pdf\%20reports/2010-08_KeeferCaudill\%20WIL\%20lit\%20review\%20\%28FINAL\%29.pdf.]

Moore, A.M., 1964, Compilation of water-temperature data for Oregon streams: U.S. Geological Survey Open-File Report 64-115, 134 p. + 1 pl. [Also available at http://pubs.er.usgs.gov/usgspubs/ofr/ofr64115.]

Moore, A.M., 1967, Correlation and analysis of water-temperature data for Oregon streams: U.S. Geological Survey Water-Supply Paper 1819-K, 53 p. plus 1 pl. (Also available at http://pubs.er.usgs.gov/usgspubs/wsp/wsp1819K.)

National Marine Fisheries Service, 2008, Willamette Basin Biological Opinion-Endangered Species Act Section 7(a)(2) Consultation: National Oceanic and Atmospheric Administration Fisheries Log Number F/NWR/2000/02117 [variously paged], accessed July 29, 2013, at http://www.nwr.noaa.gov/hydropower/willamette_opinion/index.html. 
Oregon Department of Fish and Wildlife and the National Marine Fisheries Service, 2011, Upper Willamette River conservation and recovery plan for Chinook salmon and steelhead: Oregon Department of Fish and Wildlife and the National Marine Fisheries Service, Northwest Region, Final Report, 462 p., accessed, July 23, 2013, at http://www.nmfs.noaa.gov/pr/pdfs/recovery/chinook_steelhead_upperwillametteriver.pdf.

Rounds, S.A., 2007, Temperature effects of point sources, riparian shading, and dam operations on the Willamette River, Oregon: U.S. Geological Survey Scientific Investigations Report 2007-5185, 34 p. [Also available at http://pubs.usgs.gov/sir/2007/5185.]

Rounds, S.A., 2010, Thermal effects of dams in the Willamette River Basin, Oregon: U.S. Geological Survey Scientific Investigations Report 2010-5153, 64 p. [Also available at http://pubs.usgs.gov/sir/2010/5153/.]

Rounds, S.A., and Buccola, N.L., 2015, Improved algorithms in the CE-QUAL-W2 water-quality model for blending dam releases to meet downstream water-temperature targets: U.S. Geological Survey Open-File Report 2015-1027, 36 p. [Also available at http://dx.doi.org/10.3133/ofr20151027.]

TetraTech, 2013, Willamette River floodplain restoration study draft integrated feasibility report/environmental assessment, March 2013: Prepared for U.S. Army Corps of Engineers, Portland District, 207 p. [Also available at http://www.nwp.usace.army.mil/Portals/24/docs/announcements/EA/WRFS_EA_draft_feasibility.pd f.]

U.S. Army Corps of Engineers, 1997, Middle Fork Willamette River, Oregon fisheries restoration: U.S. Army Corps of Engineers reconnaissance report, 355 p.

U.S. Army Corps of Engineers, 2012, Willamette Basin annual water quality report for 2011—Final Report: U.S. Army Corps of Engineers report, 123 p.

U.S. Army Corps of Engineers, 2015, Data query: Web site, accessed October 21, 2015, at http://www.nwd-wc.usace.army.mil/perl/dataquery.pl. 


\section{Appendix A}

Average temperatures from the three environmental scenarios (wet, normal, and dry) for several relevant fish-use periods were compiled in figure A1 for five locations in the 13.8mi Middle Fork Willamette River reach between Hills Creek Dam and Lookout Point Lake. The first two periods in figure A1 (May 1-July 1, and July 1-September 1) are during the fish rearing and migration period. The second period (September 1-October 15) is the fish-spawning period. The third period (October 15December 31) is the egg incubation period. Similarly, compiled average temperatures for the same fishuse periods immediately downstream of Dexter Dam are shown in figure A2.

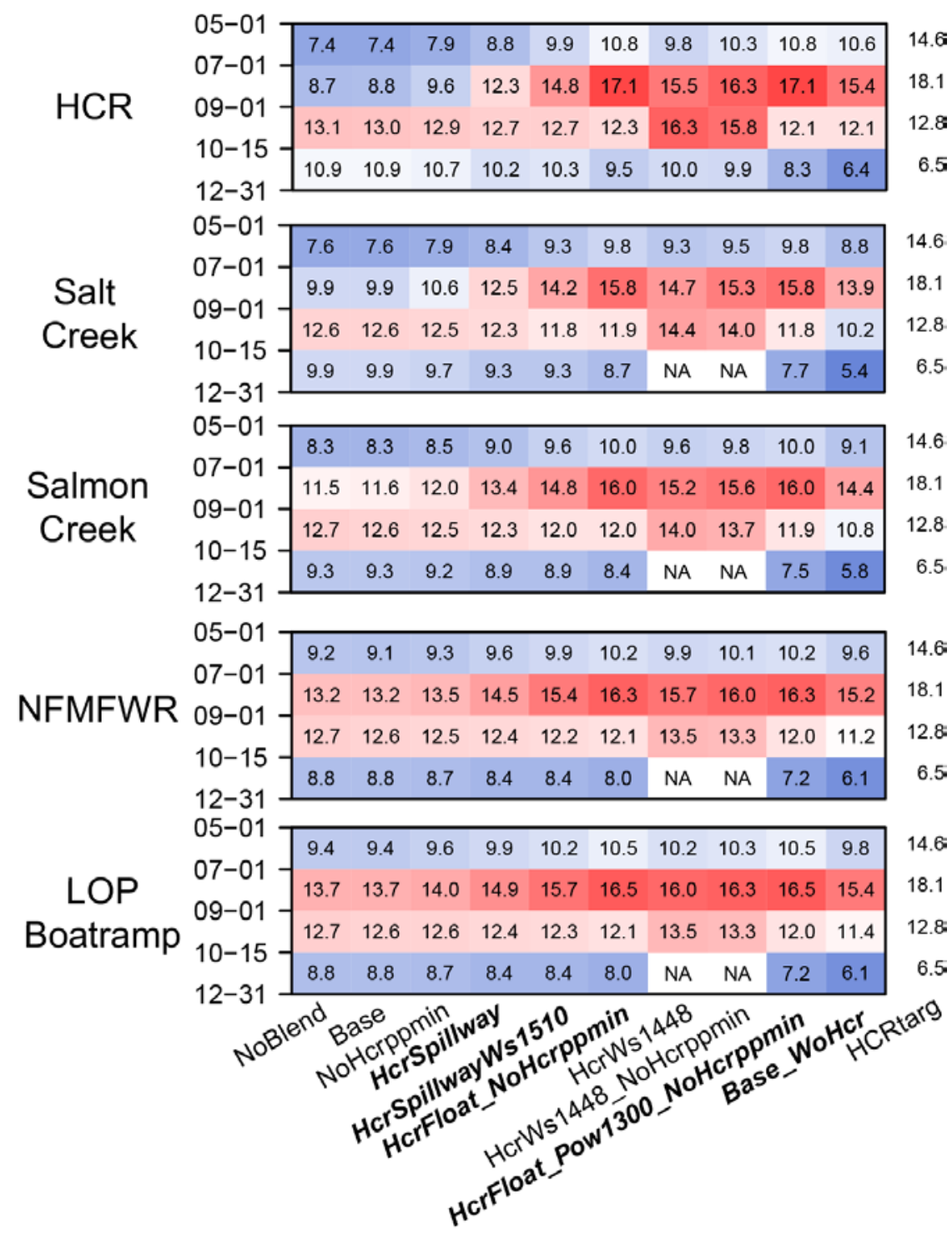

Figure A1. Simulated Middle Fork Willamette River water temperatures between Hills Creek Dam and Hampton Landing boat ramp at the head of Lookout Point Lake averaged across several fish-use periods (rearing, rearing, spawning, incubation) for each operational and structural scenario at Hills Creek Dam, Oregon. Water temperatures are averaged across wet, normal, and dry scenarios. Scenarios are ordered by estimated emergence day at the head of Lookout Point Lake, from left to right (table 7). Dates are shown in MM-DD format. Black text indicates operational scenarios and black italic text indicates structural scenarios. Values below and above 11.0 degrees Celsius are shaded blue and red, respectively. See table 4 for an explanation of the named scenarios. 


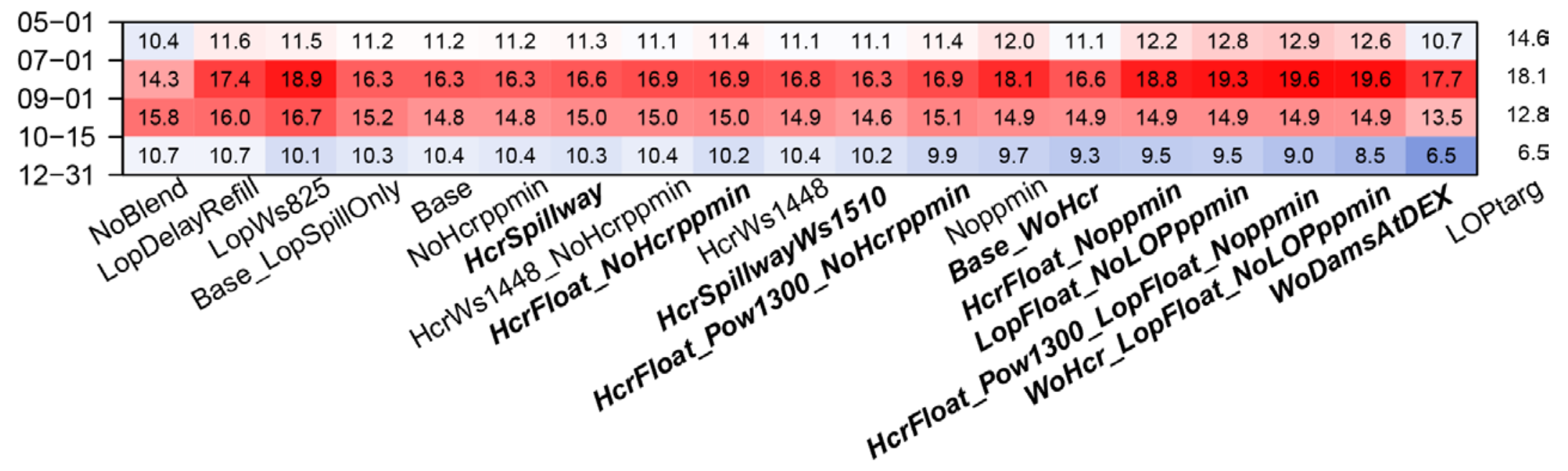

Figure A2. Simulated water temperatures downstream of Dexter Dam, Oregon, averaged across several fish-use periods (rearing, spawning, incubation) for each operational and structural scenario. Water temperatures are averaged across wet, normal, and dry scenarios. Scenarios are ordered by estimated emergence day just downstream of Dexter Dam, from left to right (table 7). Dates are shown in MM-DD format. Black text indicates operational scenarios and bold italic text indicates structural scenarios. Values below and above 11.0 degrees Celsius are shaded blue and red, respectively. See table 4 for an explanation of the named scenarios. 
Publishing support provided by the U.S. Geological Survey Science Publishing Network, Tacoma Publishing Service Center

For more information concerning the research in this report, contact the Director, Oregon Water Science Center

U.S. Geological Survey

2130 SW 5th Avenue

Portland, Oregon 97201

http://or.water.usgs.gov 
อ

울

西



害

을

沓

흘

홀

잌

응

.

을

를

$\stackrel{\infty}{\exists}$

굴

急

言

항

爱

疋

옥

은

ISSN 2331-1258 (online) 